Check for updates

Cite this: RSC Adv., 2022, 12, 1932

Received 2nd November 2021 Accepted 28th December 2021

DOI: $10.1039 / \mathrm{d} 1 \mathrm{ra0} 8053 a$

rsc.li/rsc-advances

\section{Bio-click chemistry: a bridge between biocatalysis and click chemistry}

\author{
Diego F. Rodríguez, ${ }^{a}$ Yanina Moglie, (DD b César A. Ramírez-Sarmiento, (D)cd \\ Sachin Kumar Singh, Kamal Duafg and Flavia C. Zacconi (D) *ach
}

\begin{abstract}
The fields of click chemistry and biocatalysis have rapidly grown over the last two decades. The development of robust and active biocatalysts and the widespread use of straightforward click reactions led to significant interactions between these two fields. Therefore the name bio-click chemistry seems to be an accurate definition of chemoenzymatic reactions cooperating with click transformations. Bioclick chemistry can be understood as the approach towards molecules of high-value using a green and sustainable approach by exploiting the potential of biocatalytic enzyme activity combined with the reliable nature of click reactions. This review summarizes the principal bio-click chemistry reactions reported over the last two decades, with a special emphasis on small molecules. Contributions to the field of bio-click chemistry are manifold, but the synthesis of chiral molecules with applications in medicinal chemistry and sustainable syntheses will be especially highlighted.
\end{abstract}

rscilirsc-advances 


\section{Introduction}

Chemoenzymatic syntheses are powerful methodologies for the creation of complex molecular structures and functionalities. ${ }^{1}$ The development of processes which combine biocatalysis and chemical synthesis has rapidly increased over recent years. The two main pillars of innovation in the field are the generation of more active, selective, and stable biocatalysts, ${ }^{2}$ and the development of new synthetic procedures in water, allowing for highly efficient, and sustainable one-pot procedures. ${ }^{3}$

The term click chemistry was introduced by Sharpless in 2001, comprising highly efficient and reliable reactions enabling the rapid construction of structural and functional diversity through the union of small building blocks. Commonly these reactions have very high inherent driving forces, thus avoiding tedious chromatographic work-up. ${ }^{4}$ Evidently, the concept of click chemistry is largely inspired by nature's "synthetic toolbox", and it is not surprising that the merger of click chemistry and biocatalysis exhibits great potential for the synthesis of complex molecular structures.

The increasing demand for sustainable processes is fostering the development and establishment of new synthetic tools. Among these tools, click chemistry and biocatalysis are of utmost importance, since they are characterized by their high selectivity and orthogonality, mild reaction conditions avoiding protecting groups, efficiency, reliability, and user-friendliness. ${ }^{5}$ The growing interest in click chemistry and biocatalysis in recent years is reflected by the drastic increase in the number of publications on the topic (Fig. 1). It is not surprising that the combination of these two disciplines, which we propose to call

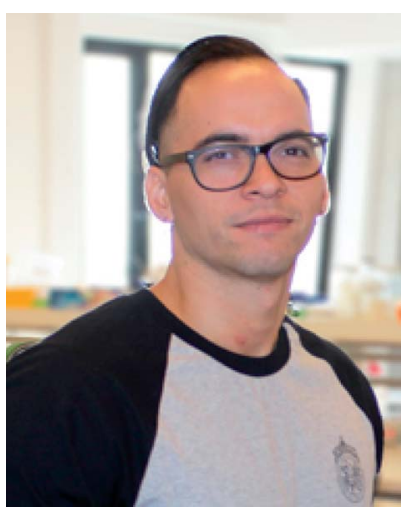

Dr César A. Ramírez-Sarmiento obtained his PhD in Sciences at Universidad de Chile, Chile. Currently, Dr RamirezSarmiento in an Assistant Professor at the Institute for Biological and Medical Engineering, Pontificia Universidad Católica de Chile. Dr RamírezSarmineto research focuses on working on protein folding, function, and evolution. The computational and experimental research developed by his group focuses on the discovery and engineering of plastic-degrading enzymes for their utilization as biocatalysts and on the study of structural interconversions in transcription regulators for their repurposing as biosensors.

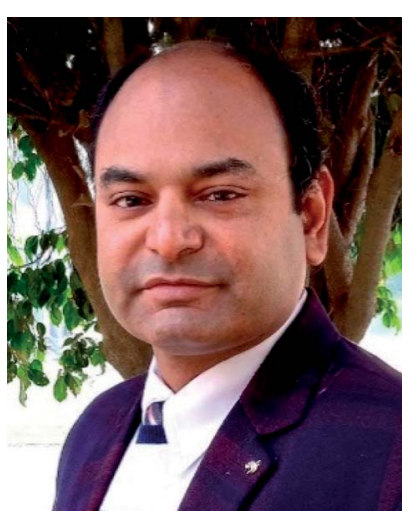

Dr Sachin Kumar Singh, a Professor at School of Pharmaceutical Sciences (Lovely Professional University, India) holds his PhD degree in Pharmaceutical Sciences (Karpagam University, India). Dr Singh has published more than 175 research papers, 11 book chapters, and he has filed 10 patents. He has a keen desire to bring his formulations into market for patients suffering from diabetes and he is set to transfer the technologies developed to pharma and nutraceutical industry. In 2020, he received Dr B.C. Deb memorial award by Indian Science Congress Association and the Bharat Shiksha Ratan Award given by Global Society for Health and Educational Growth, India.

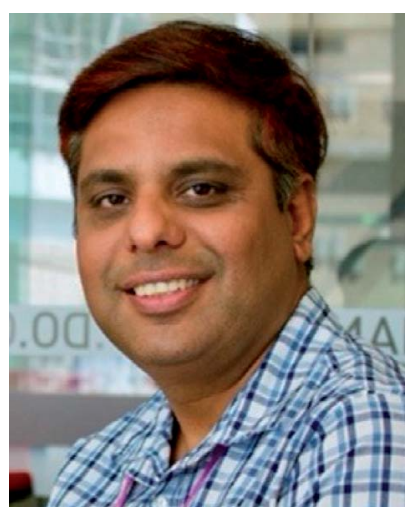

Dr Kamal Dua, Lecturer, Discipline of Pharmacy, Graduate School of Health, University of Technology Sydney, has a research experience of more than 12 years working in the field of drug delivery targeting inflammatory diseases. Dr Dua is also a Node Leader of Drug Delivery Research in the Centre for Inflammation at Centenary Institute/UTS, where the targets identified from the research projects are pursued developing novel formulations as the first step towards translation into clinics. Dr Dua research in two complementary areas; drug delivery and immunology, specifically addressing how these disciplines can advance one another helping community to live longer and healthier.

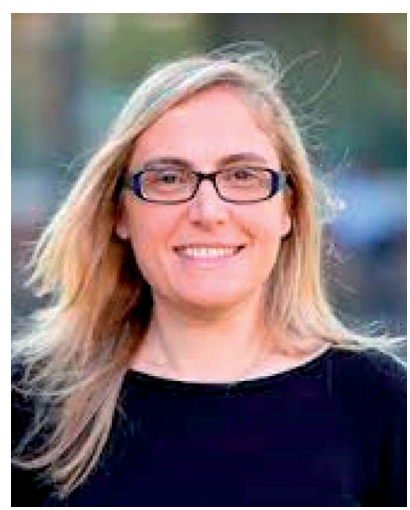

Dr Flavia C. Zacconi obtained her PhD in Chemistry from the Universidad Nacional del Sur (UNS), Argentina. Currently, her Associate Professor position is share between the Faculty of Chemistry and Pharmacy and the Institute for Biological and Medical Engineering, Pontificia Universidad Católica de Chile. She has a research experience in organic chemistry, medicinal chemistry, and biomaterials. $\mathrm{Dr}$ Zacconi research focuses on the intersections of organic chemistry, medicinal chemistry, engineering, and biological chemistry, developing multi- and interdisciplinary projects to understand the complexity of bioactive systems. Additionally, Dr Zacconi acts as a reviewer for international journals and national and international projects; and she has published research papers, book chapters, and books. 
bio-click chemistry, has given rise to a myriad of highly interesting developments and has led to a significant impact on the synthesis of structurally diverse molecules, such as chiral amino alcohols, triazoles, amides, cycloadducts, thioethers, and others. In addition, bio-click methodologies show a synergy oftentimes allowing for shorter, stereoselective and efficient synthetic routes.

The present review focuses on syntheses in which biocatalytic processes and click reactions were used in combination. Recent reviews have focused on specific applications of click chemistry and biocatalysis in the in situ generation of inhibitors, ${ }^{6,7}$ the immobilization and modification of enzymes, ${ }^{8}$ or the generation of semisynthetic enzymes. ${ }^{9}$ However, the discrete topic of bio-click chemistry has yet to be approached in depth. We seek to fill this gap and discuss the most important aspects of the development of bio-click methodologies, as well as their main advantages and limitations.

\section{Bio-click chemistry}

Organic chemistry has a sheer endless set of reactions allowing for the generation of molecular diversity and complexity. Chlorophyll, $^{\mathbf{1 0}}$ taxol, $^{\mathbf{1 1}, 12}$ and human lysozyme ${ }^{\mathbf{1 3}}$ are only a few examples of highly important complex molecules obtained through elegant chemical syntheses. Albeit highly sophisticated, organic synthesis is undergoing constant improvements ${ }^{\mathbf{1 4}}$ especially through the development of more selective, efficient, and sustainable reactions. The interconnection of different disciplines, such as biocatalysis and click chemistry, is essential to achieve these goals (Fig. 2).

Click chemistry is generally outlined by a group of reactions with desirable characteristics for biocompatible reactions or bioconjugations: reliability, effectiveness, protecting groupfree, high yielding, and easy to purify (often without any chromatography). The fact that click chemistry has become an integral part of the synthetic toolbox is demonstrated by its success in chemical synthesis, drug discovery, medicinal chemistry, ${ }^{15}$ molecular labelling, ${ }^{16}$ polymer synthesis, ${ }^{17}$ and others.

The cutting-edge example for click chemistry is (i) the copper-catalyzed 1,3-dipolar cycloaddition of terminal alkynes

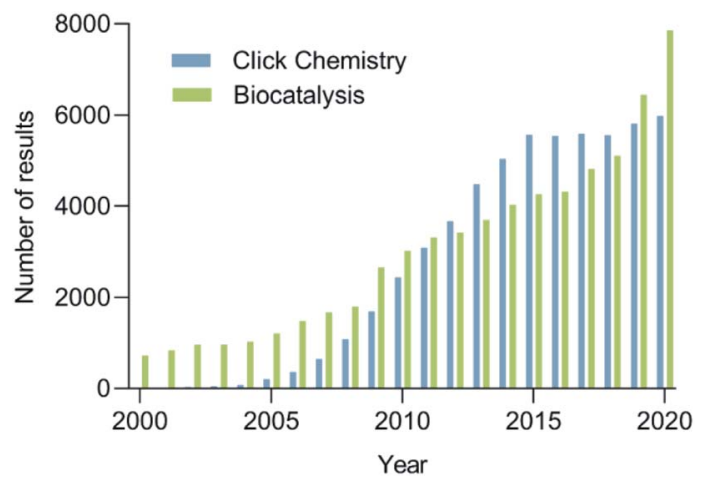

Fig. 1 The number of results to the search for click chemistry (blue) and biocatalysis (green) in Scopus per year between 2000-2020. and organic azides (CuAAC). Nevertheless, many other transformations are classified as click reactions as well (ii) the DielsAlder reaction, (iii) additions to alkenes, (iv) nucleophilic opening of strained rings, (v) non-aldol carbonyl transformations, and (vi) addition reactions to alkynes. ${ }^{18}$ It has to be clarified, that although click reactions are regio- and stereospecific, they are not necessarily enantioselective. ${ }^{4}$ This shortcoming can be overridden by the merger of click chemistry with enantioselective biocatalysts such as enzymes.

Biocatalysis comprises the use of purified enzymes, cell-free extracts or whole microorganisms as catalysts in a vast array of transformations, rendering them as excellent and sustainable methods for the construction of complex molecular structures, while fulfilling green chemistry principles. ${ }^{19}$ However, enzymes have inherent limitations often preventing their widespread use in synthesis: rather low operational stability, inhibition by substrates or products, limited tolerance of non-natural substrates and limited applicability in organic solvents. Innovative technologies, such as protein engineering and enzyme immobilization, have emerged to overcome these drawbacks and limitations. ${ }^{2}$ Many enzymes obtained by protein engineering are more robust, stable and capable to transform nonnatural substrates. Immobilized enzymes generally present outstanding operational stability, an easy removal from the reaction medium and the capability of repetitive recycling.

Enzymatic processes allowing for the synthesis of complex molecules under highly sustainable and green conditions are increasingly popular. Various drug molecules commonly synthesized through traditional catalytic processes are eventually produced by chemoenzymatic methods, thus improving process efficiencies and substantially reducing waste generation. ${ }^{20,21}$

A state-of-the-art example is the biocatalytic synthesis of the HIV treatment candidate islatravir, as reported by Huffman and co-workers. ${ }^{22}$ In this process, five enzymes obtained by directed evolution (two immobilized enzymes) and four auxiliary enzymes were applied towards the generation of islatravir from simple achiral building blocks in a three-step cascade reaction (Fig. 3). The target molecule was obtained in 51\% overall yield, with high atom economy, using water as solvent, avoiding intermediate purification and in less than half of the number of steps compared to the conventional chemical synthesis. ${ }^{22}$

Although, Caruso et al. used the term bio-click chemistry in a study towards the functionalization of polymer drug vehicles, ${ }^{23}$ a more exhaustive review of the interface between click chemistry and biocatalysis is necessary. Considering the potential for the development of highly efficient, sustainable, and selective processes, a profound impact of bio-click methods on the field can be envisaged.

It should be noted that the term "bio-click chemistry" differs markedly from click chemistry, as it interconnects the latter with biocatalytic processes. In many cases, this allows for the development of greener processes. However, it must be clarified that the examples covered in this review are based not only on sustainability or higher yields, but rather cover a broad spectrum of cases allowing us to show the current advantages and limitations of bio-click chemistry. 


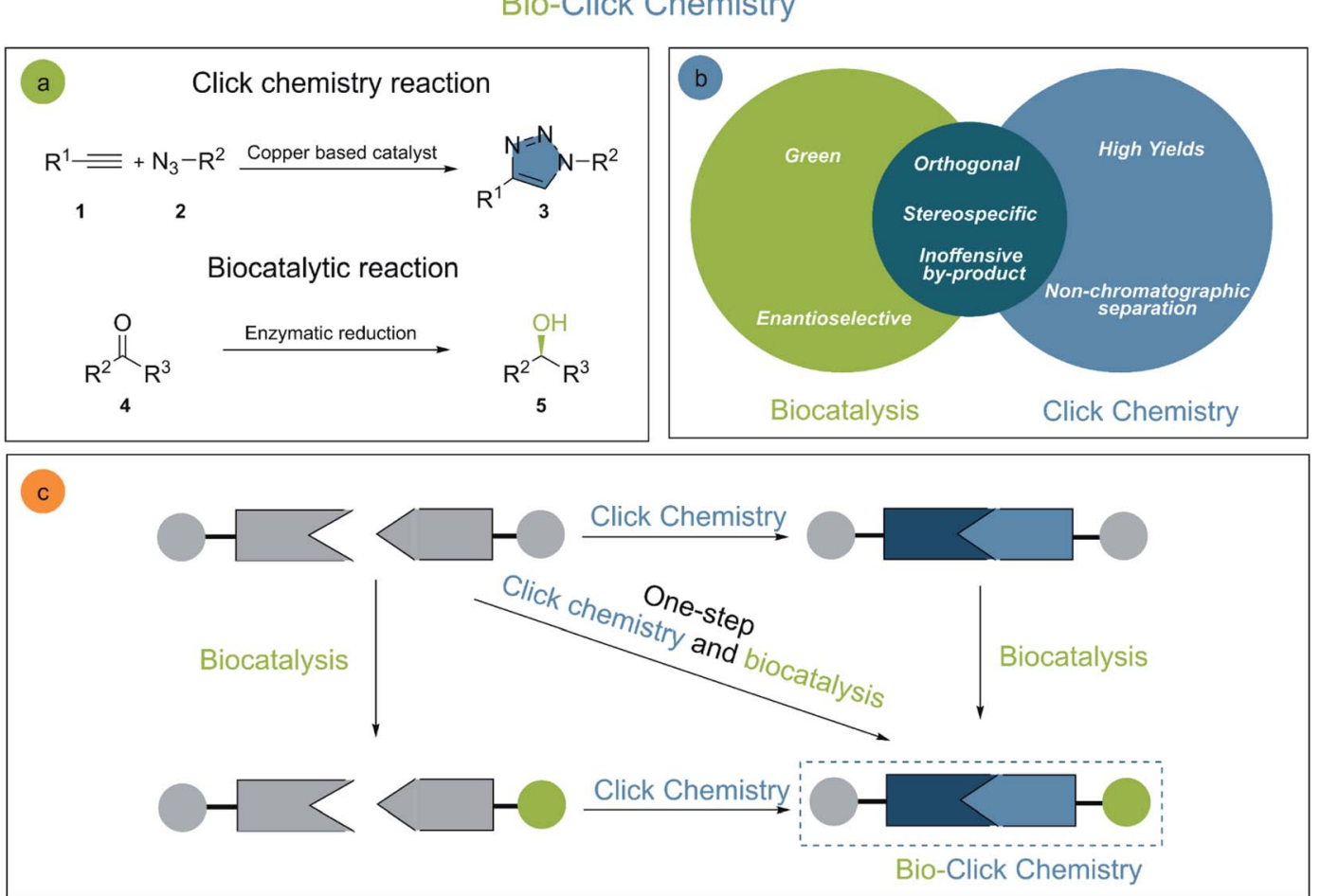

Fig. 2 (a) General click chemistry and biocatalysis reactions, (b) bio-click chemistry interface and (c) schematic representation of bio-click chemistry cooperation for the synthesis of small molecules.

\section{Bio-click reactions}

Click chemistry is a dynamic and growing field, continually leading to new transformations. Many of these developments are predominantly focused on bioconjugation and applications in materials science. ${ }^{24}$ Examples for new transformations characterised as click reactions are the sulfur(vi) fluoride exchange (SuFex) ${ }^{25}$ and the synthesis of azides from primary amines $^{\mathbf{2 6}}$ respectively. Nevertheless, interactions of the latter with biocatalysis for the creation of new molecules are still missing. Significant cooperation between click chemistry and biocatalysis has been reported for CuAAC-, Diels-Alder-, epoxide-opening- and thiol-Michael reactions, and these studies will be discussed in further detail.

\subsection{CuAAC and biocatalysis}

CuAAC is probably the most representative click reaction. It allows for the synthesis of 1,2,3-triazoles from organic azides and alkynes in the presence of a copper-(I)-catalyst (Scheme 1). The 1,2,3-triazole ring has shown great value as a pharmacophore, and several reviews focused on the potential of this invaluable motif in medicinal chemistry. ${ }^{15,27}$ Regarding the bioclick approach, the main focus in literature is the combination of CuAAC with oxidoreductases and hydrolases respectively.

3.1.1 CuAAC and oxidoreductases. The most common application of click reactions combined with oxidoreductases is for the synthesis of highly enantiopure $\beta$-hydroxytriazoles 13. These compounds present excellent pharmacological properties, as they are able to act as potential HIV protease inhibitors $^{28}$ and $\beta$-adrenergic receptor blockers. ${ }^{29}$ Enantiopure $\beta$-hydroxytriazoles can be generally obtained by three distinct approaches: (a) bioreduction of $\alpha$-chloro/bromo-acetophenones or $\alpha$-azidoacetophenones with subsequent CuAAC reaction, (b) the generation of $\beta$-ketotriazoles and subsequent bioreduction, (c) a simultaneous one-pot bioreduction and triazole formation (Scheme 1).

In 2008, Hua and co-workers reported the use of a recombinant carbonyl reductase from Candida magnoliae (CMCR) and an alcohol dehydrogenase from Saccharomyces cerevisiae (Ymr226c), with glucose dehydrogenase as cofactor-regeneration enzyme, for the enzymatic reduction of $\alpha$-azidoacetophenone. ${ }^{29}$ Both enzymes were able to catalyze the formation of the

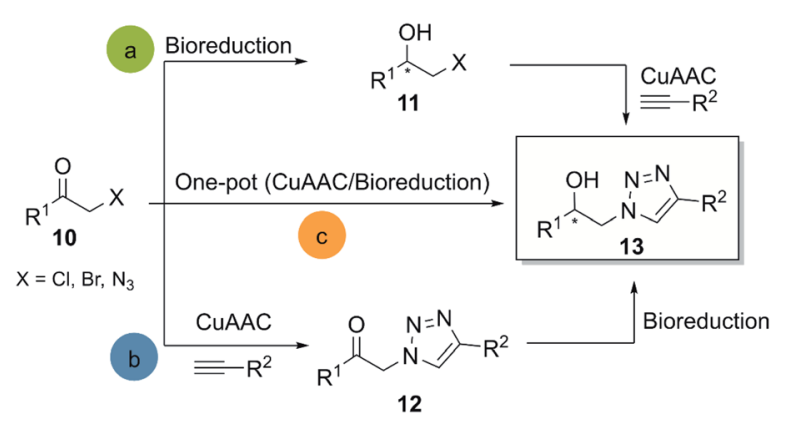

Scheme 1 General methodologies for the chemo-biocatalytic synthesis of $\beta$-hydroxytriazoles. 

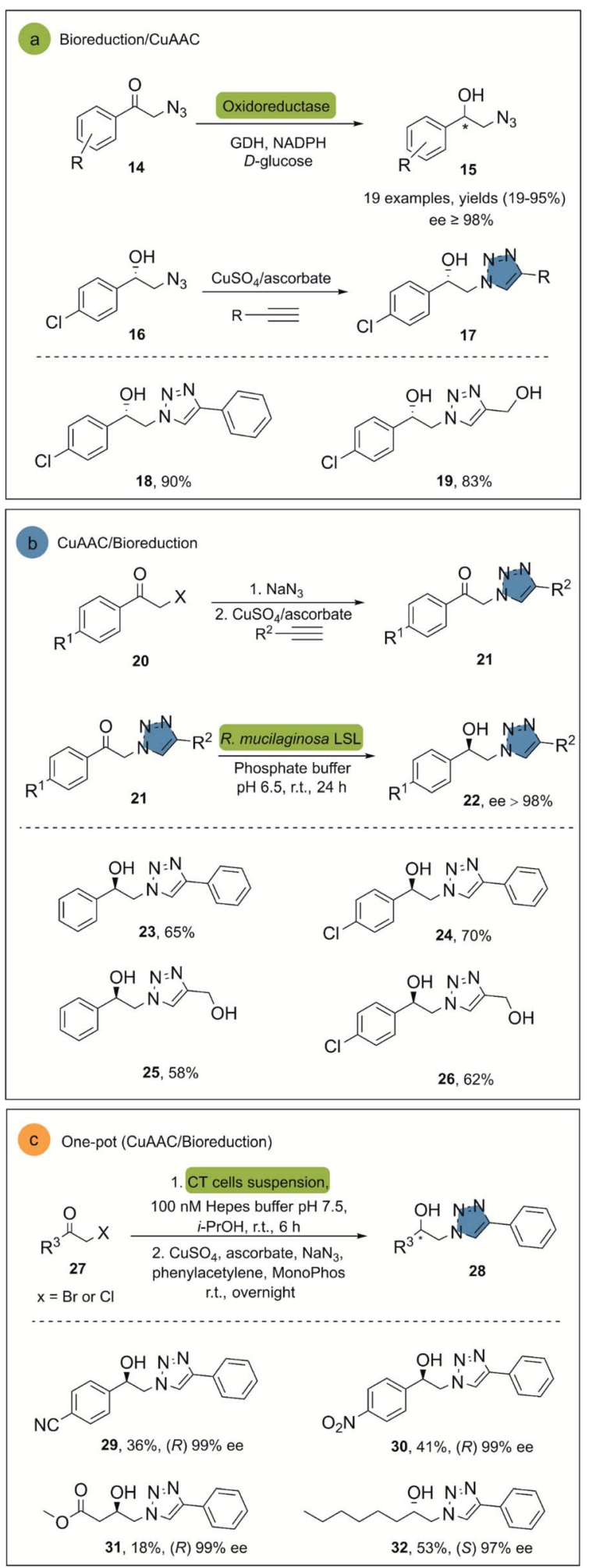

Scheme 2 (a) Synthesis of $\beta$-blocker analogues containing 1,2,3-triazoles moieties, (b) stereoselective reduction of $\beta$-ketotriazoles with $R$. mucilaginosa LSL, (c) one-pot whole-cell catalysis and CuAAC for the conversion of $\alpha$-haloketones to $\beta$-hydroxytriazoles.

corresponding chiral alcohol in excellent optical purities, good yields and with wide substrate scope. After the successful bioreduction of 2-azidoacetophenones 14, the desired 1,2,3triazoles 17 were obtained in high yields, using $\mathrm{CuSO}_{4}$ and sodium ascorbate as catalytic system (Scheme 2a).

Another interesting example is the direct synthesis of enantioenriched $\beta$-hydroxytriazoles from the corresponding haloketones and $\beta$-ketotriazoles. ${ }^{30}$ In this approach, a whole-cell procedure of wild type Rhodotorula mucilaginosa LSL successfully catalyzed the one-pot enantioselective bioreduction of the substrate in water at room temperature, although only four examples were reported under these conditions (Scheme $2 b$ ). Notably, the reactants necessary for the ketotriazole formation, such as sodium azide and copper sulfate, did not affect the $R$. mucilaginosa LSL system in its catalytic activity. This represents an important advantage, avoiding purification steps and the manipulation of organic azides, often exhibiting explosive properties. ${ }^{31}$

Janssen and co-workers described an alternative system for the synthesis of $\beta$-hydroxytriazoles using a one-pot methodology. ${ }^{32}$ The developed system consists of the E. coli strain MC1061, which overexpresses enzymes such as alcohol dehydrogenases (ADH) and halohydrin dehalogenases (HHDH) with different stereospecificities. The construct that overexpressed $(R)$-stereospecific $(\mathrm{ADH})$ and $(\mathrm{HHDH})$ was called CT-cells and produce $(R)$-enantiomers, while the BT-cells form the $(S)$-enantiomers in high enantiomeric purity, albeit only moderate yields. The catalyst for the click reaction was $\mathrm{CuSO}_{4}$ with sodium ascorbate in the presence of MonoPhos as ligand, increasing the CuAAC reaction rate ${ }^{33}$ (Scheme 2c).

Chiral diols are a group of compounds widely used as organocatalysts and intermediates for the preparation of chiral heterocycles. ${ }^{34,35}$ Gotor and co-workers reported the synthesis of dihydroxytriazoles 37 through a highly efficient chemoenzymatic procedure under mild reaction conditions. ${ }^{36}$ In this two-stage one-pot procedure, the recombinant enzyme ADH-A from Rhodococcus rubber overexpressed in E. coli (Prelog-
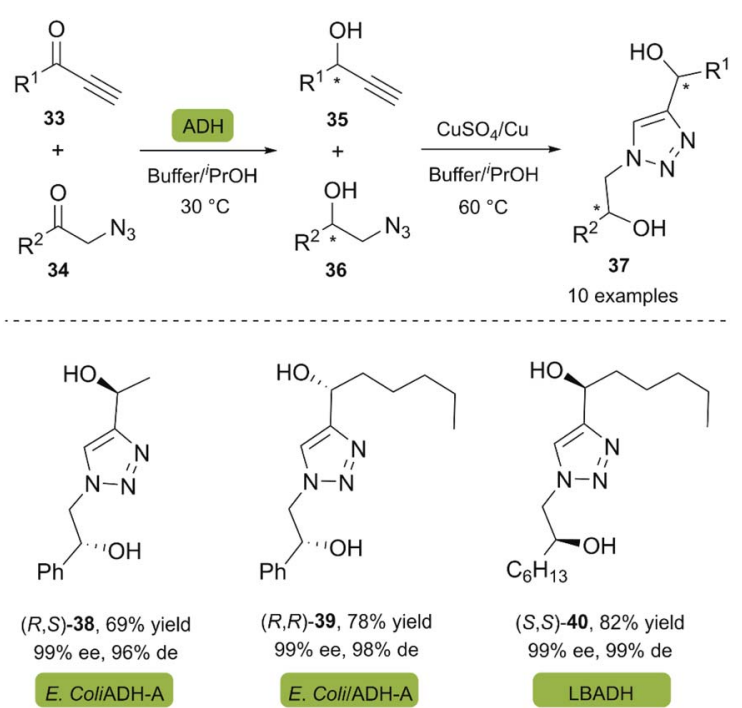

Scheme 3 Synthesis of dihydroxytriazoles from chemoenzymatic approach. 
enzyme) and a commercially available LBADH from Lactobacillus brevis (anti-Prelog-enzyme) were used for the bioreduction of several alkynones 33 and $\alpha$-azido ketones $\mathbf{3 4}$ in a phosphate buffer with 2-propanol. A copper wire was used as a reusable catalyst for the click reaction, supplemented by a catalytic amount of copper sulfate (Scheme 3).

A powerful methodology for asymmetric ketone reduction was reported by Omori and co-workers in 2013, using whole cells from plant tissue from carrots (Daucus carota). The main advantage of this approach is its simplicity, economy of the process and the easy availability. The reaction features the onepot bioreduction of azidoacetophenones ( $p, m$-substituted) $\mathbf{4 1}$ with the subsequent CuAAC reaction using the Sharpless-Fokin catalyst (Scheme 4). ${ }^{37}$ The products were obtained in moderate yields but excellent enantiomeric excess (>99\%). However, a disadvantage of this process is the rate of the bioreduction, requiring 5-7 days for completion. This impedes the implementation of a single-stage one-pot procedure, since the click reaction occurs very fast, and non-reduced triazoles are insoluble in water.

Dioxygenases are versatile biocatalysts that have been used in the chemoenzymatic synthesis of chiral hydroxyazides. In 2011, the Stefani group reported the enzymatic dihydroxylation of arenes 45 catalyzed by whole-cell $P$. putida F39/D en route to chiral azides 47 . The subsequent click reaction between 47 and several alkynes was achieved with the Sharpless-Fokin catalyst in $t$ - $\mathrm{BuOH}: \mathrm{H}_{2} \mathrm{O}$ or toluene $: \mathrm{H}_{2} \mathrm{O},{ }^{38}$ and the corresponding triazolylconduritols $\mathbf{4 8}$ were obtained in good to excellent yields (Scheme 5).

3.1.2 CuAAC and hydrolases. Over the last decade, chemoenzymatic methods based on the combination of hydrolases and the click CuAAC reaction have been successfully implemented for peptide-triazole synthesis $\mathbf{5 5}$ and the kinetic resolution (KR) of racemic secondary alcohols 56 (Scheme 6).

Enzymatic aminolysis is an excellent environmentallyfriendly alternative to coupling reactions generally used in amide synthesis, and its importance is expected to increase over the coming years. ${ }^{39}$ However, the enzymatic formation of the peptide bond usually requires a high amount of biocatalyst, which is a major drawback. The sustainability of these

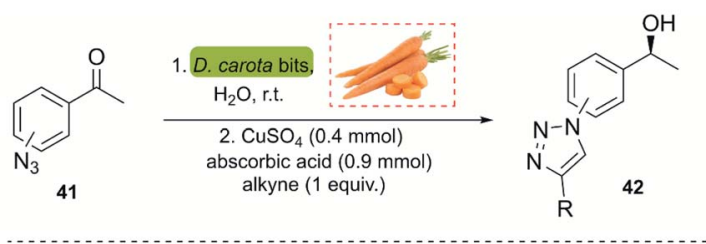

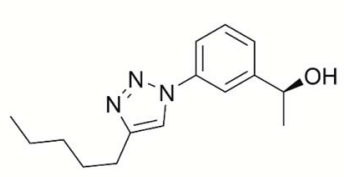

(S)- $-43,57 \%$ yield, ee> $99 \%$

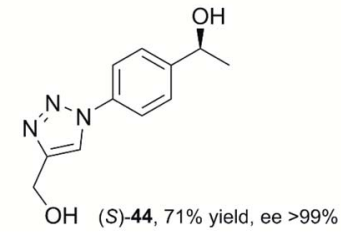

Scheme 4 A chemoenzymatic methodology for the synthesis of chiral hydroxytriazole.
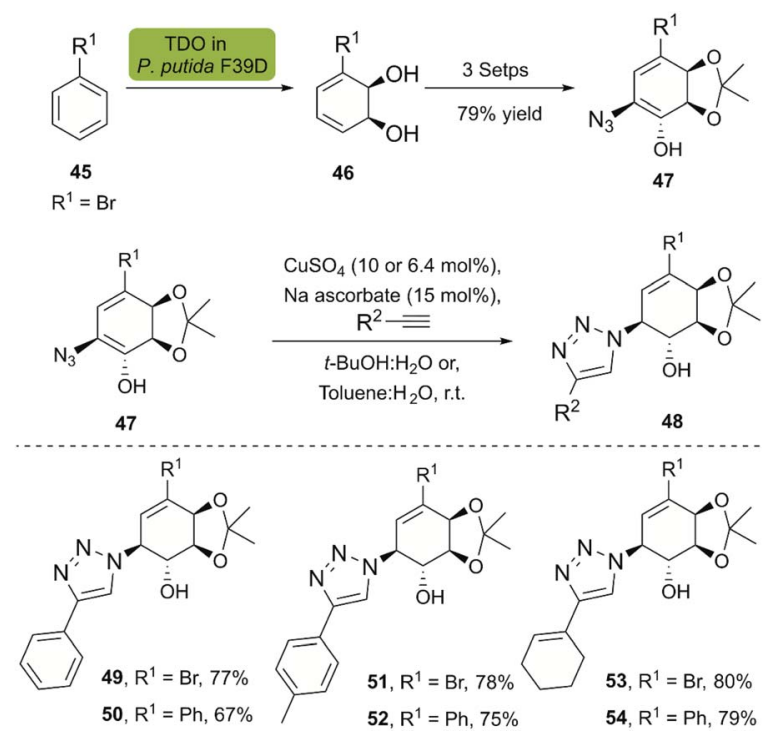

Scheme 5 Chemo-enzymatic synthesis of the bromoazidoconduritol derivative, and synthesis of triazolylconduritols.
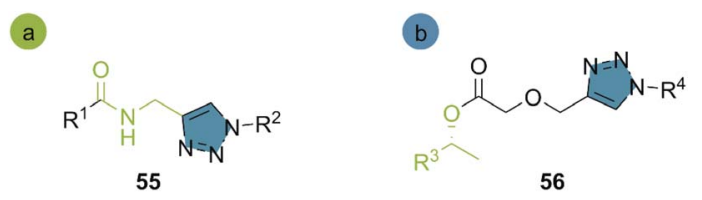

Scheme 6 Representative structures obtained by chemoenzymatic hydrolases/CuAAC reactions in (a) peptidomimetic synthesis (b) kinetic resolution of racemates.

processes was greatly improved with the implementation of immobilized enzymes, which are usually very stable and easily removed from the reaction medium, playing a crucial role in green amide syntheses.

Due to their structural and electronic similarity, 1,2,3-triazoles can act as peptidomimetic amides. Specifically, the 1,4disubstituted 1,2,3-triazoles are bioisosteres of trans-amide compounds. ${ }^{40}$ Due to the importance of peptides as pharmacologically active compounds, the triazol-ring represents an excellent alternative for the synthesis of peptides with increased metabolic stability, as well as biologically-active natural product analogs difficult to obtain through conventional synthesis.

In 2013, the Müller group reported the first enzymatic aminolysis catalyzed with lipases and a subsequent CuAAC reaction. ${ }^{41}$ For the aminolysis reaction, different commercially available immobilized lipases were studied. However, only Novozym ${ }^{\circledR} 435$ and Immobead ${ }^{\circledR} 150$ successfully catalyzed the reaction of methyl esters $\mathbf{5 7}$ with propargyl amine $\mathbf{5 8}$. Novozym ${ }^{\circledR} 435$ (Candida antarctica lipase B [CALB] immobilized in Lewatit VP OC 1600) proved to be superior and achieved 68\% conversion in $24 \mathrm{~h}$. The optimized reaction conditions can be applied to a broad range of substrates and generally achieve good yields. The biocatalytic synthesis of propargylamides was then coupled to the $\mathrm{CuAAC}$ reaction using $\mathrm{CuO}_{2}$ /benzoic acid as 


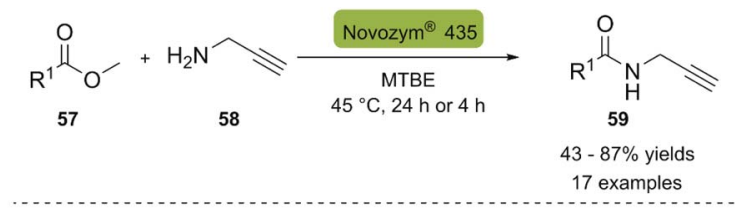<smiles>C#CCNC(=O)CCc1ccccc1</smiles><smiles>C#CCNC(=O)COc1ccccc1</smiles><smiles>C#CCNC(=O)CSc1ccccc1</smiles><smiles>C#CCNC(=O)C#Cc1ccccc1</smiles>

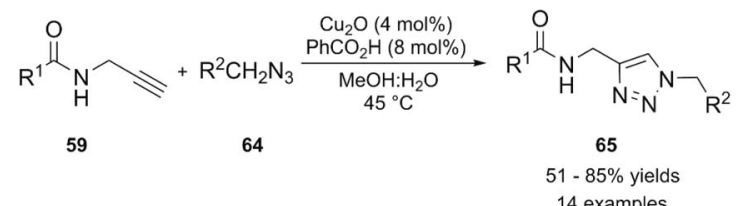<smiles>O=C(CCc1ccccc1)NCc1cn(Cc2ccccc2)nn1</smiles><smiles>O=C(NCc1cn(CSc2ccccc2)nn1)c1ccco1</smiles>

$67,85 \%$

Scheme 7 Synthesis of propargyl amides with CAL-B (Novozym ${ }^{\circledR}$ 435) and consecutive three-component synthesis of the amido methylsubstituted 1,2,3-triazoles.

catalyst, and $\mathrm{H}_{2} \mathrm{O}: \mathrm{MeOH}(1: 1)$ as solvent system. The amidetriazole products 66-67 were obtained with yields between 5185\% (Scheme 7).

Based on the aforementioned studies, the Müller group reported the consecutive seven-component synthesis of triamides with a triazole moiety in $2019 .^{42}$ This approach incorporated the biocatalytic aminolysis-CuAAC reaction in a new 5-stage multicomponent one-pot synthesis. The reactions featured (i) the synthesis of a diamide with a methyl ester group, from a 4component Ugi-reaction, (ii) the propargylamide synthesis catalyzed by Novozym ${ }^{\circledR} 435$, (iii) a CuAAC reaction and (iv) a Suzuki cross-coupling to the final product. This sequential one-pot procedure allowed to synthesize compound 70 in 36\% overall yield. The described method allows for the generation of

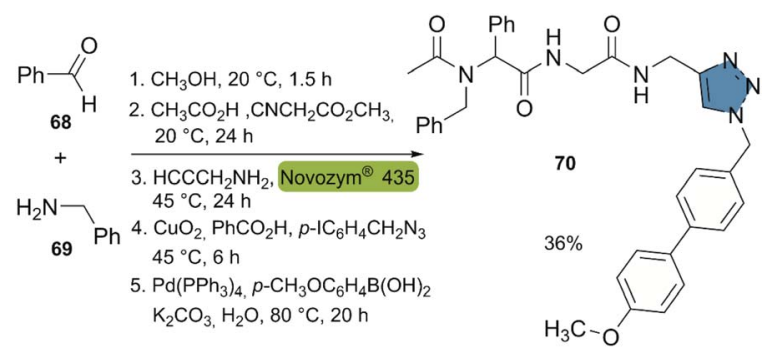

Scheme 8 Consecutive seven-component sequence: Ugi reaction, CALB-catalyzed aminolysis, CuAAC, Suzuki coupling for the synthesis of product 70 . compound libraries, in an easy way without the need for intermediate purification (Scheme 8).

A second application of the hydrolases combined with CuAAC are the kinetic resolutions of racemic mixtures. In this context, Büyükadali et al. described the one-pot synthesis of chiral benzothiophenyltriazoles and benzofuranyltriazoles in $2015{ }^{43}$ This bio-click approach produces the enantiomerically enriched homopropargylic alcohols (+) 72 using the commercially available TLIM (immobilized Thermomyces lanuginosus lipase). TLIM proved superior to other lipases, such as Novozym ${ }^{\circledR} 435$ concerning both, enantioselectivity and reaction time. Furthermore, the reaction occurs in vinyl acetate, which acts as an acyl donor and solvent (Scheme 9). Unfortunately, the amount of biocatalyst necessary was $1: 1 \% \mathrm{w} / \mathrm{w}$ with respect to the substrate, and recycling experiments of the catalyst were not reported. The concatenation of the TLIM-mediated enzymatic resolution and a click reaction was achieved through a subsequent one-pot multicomponent $\mathrm{CuAAC}$ reaction using $\mathrm{CuSO}_{4}$ $\cdot 5 \mathrm{H}_{2} \mathrm{O} / \mathrm{Na}$ ascorbate, $\mathrm{NaN}_{3}$, L-proline, and $\mathrm{Na}_{2} \mathrm{CO}_{3}$, furnishing the corresponding triazole derivatives $(+) \mathbf{7 9}$ with good yields (Scheme 9). The in situ generation of the organic azide eliminates the need of an intermediate purification process.

In 2018, Moisă et al. reported a new bio-click approach for the separation of racemic secondary alcohols 82 by simple extraction. ${ }^{\mathbf{4 4}}$ This methodology uses the enantioselectivity of the lipases of Novozym ${ }^{\circledR} 435$ and Pseudomonas fluorescens (L-AK) for the catalysis of an O-acylation of heteroarylethanols with different esters 83a-d as acylating agents. The corresponding
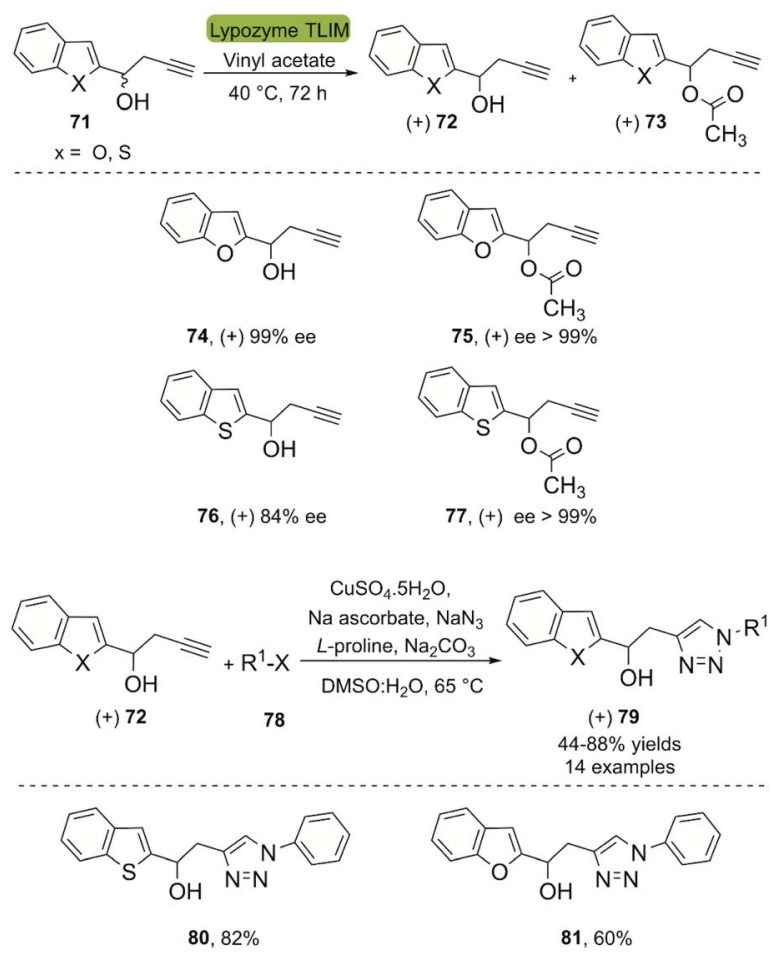

Scheme 9 Enzymatic resolution of racemic homopropargylic alcohols with TLIM and multicomponent synthesis of 1,4-disubstituted 1,2,3-triazole derivatives. 
$(R)$-product $\mathbf{8 4}$ is then subjected to a CuAAC reaction with azidofunctionalized tertiary amine 85 in the presence of CuI, furnishing the triazole quantitatively. The ionizable triazole ester was efficiently extracted with an aqueous acetic acid solution, while the $(S)$-82 alcohol was recovered from the organic phase. The alcoholysis of the triazole derivative in the presence of ethanol was catalyzed by CALB $_{\text {SWCNT }}$ (CALB covalently immobilized on single-walled carbon nanotubes) and allowed for the obtention of the (R)-82 alcohol (Scheme 10). Upscaling of the process to a multi-gram scale revealed, that there was neither a change in the selectivity of the enzymes nor in the efficiency, as reflected in virtually unchanged isolated yields of the products $(>99 \%)$.

\subsection{Diels-Alder reactions and biocatalysis}

The Diels-Alder (DA) reaction is an outstanding tool for the synthesis of cyclohexenes and other ring structures. Involving the cycloaddition of a diene and a dienophile, it has been extensively used for the synthesis of complex molecules and is one of the most powerful transformations in organic chemistry (Scheme 11). Moreover, the DA reaction is stereospecific, shows a high atom economy and reliability, and can be carried out in environmentally-friendly solvents. ${ }^{45,46}$ A hetero-Diels-Alderreaction (HAD) is equally well studied, and is a reliable alternative for the synthesis of ring structures including heteroatoms.

In contrast to the CuAAC reaction, the DA reaction can be carried out without a catalyst. However, the use of Lewis acids allows to decrease the activation energy of the DA reaction, increasing its rate and lowering the necessary reaction temperature. ${ }^{4-49} \mathrm{~A}$ further increase of the reaction rate can be achieved by the incorporation of EWG-groups in the dienophile and EDG-groups in the diene, favoring the electronic distribution necessary for the reaction to occur.

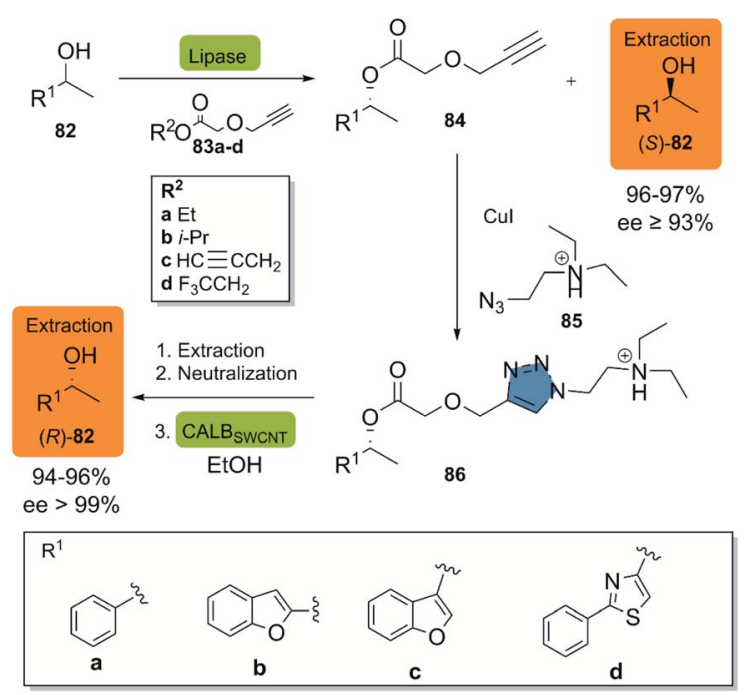

Scheme 10 Production of the two enantiomeric forms of (hetero) arylethanols by an enzymatic KR/click reaction-based separation process. This figure has been Adapted from ref. 44 with permission from the Royal Society of Chemistry.

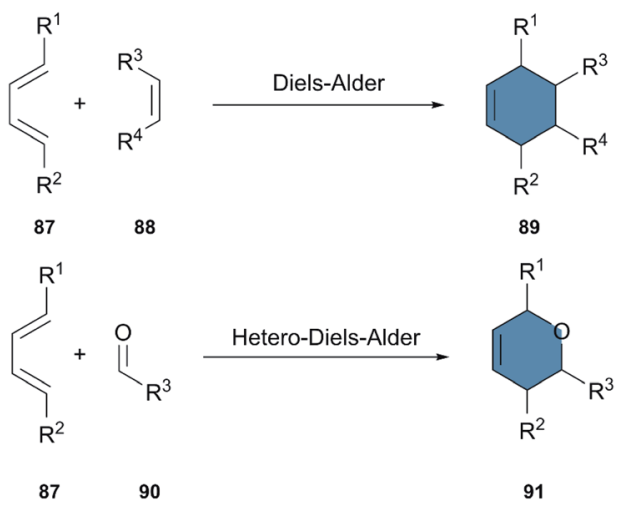

Scheme 11 Diels-Alder reaction and hetero-Diels-Alder reaction.

3.2.1 DA/HDA and oxidoreductases. The combination of DA reactions with oxidoreductases has been successfully applied in the stereoselective synthesis of complex molecules. The bio-click approach has been used for the synthesis of sorbicillin derivates, an important family of compounds from fungi, exhibiting promising biological activities. ${ }^{50}$ In 2017 , the Gulder group reported the total synthesis of bisorbicillinoids by an enzymatic oxidative dearomatization of sorbicillin 92 and a subsequent DA reaction (Scheme 12). ${ }^{51}$ In the first part of the synthesis, the enzyme SorbC catalyzed the enantioselective formation of sorbicillinol $(S)-93$ (ee $>99.5 \%$ ), followed by the rapid dimerization to the product through a DA reaction. The solvent polarity proved to be crucial for the stability of sorbicillinol $(S)-93$, when $\mathrm{CH}_{2} \mathrm{Cl}_{2}$ was used to quench the reaction, the bisorbicillinol 94 was obtained in a $27 \%$ yield in 40 minutes, without any other dimeric analogs. Different co-solvents could be used for the control of the selective formation of different

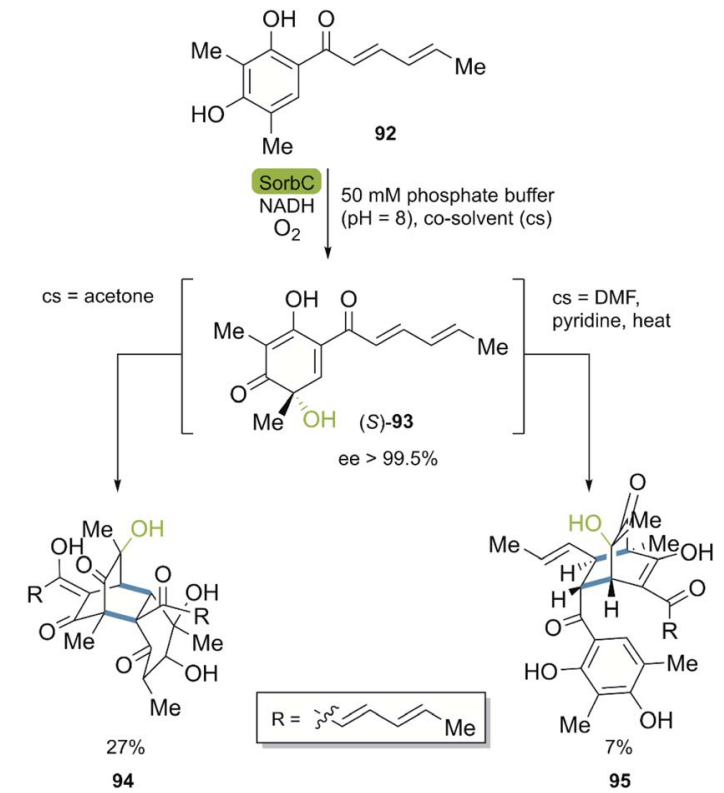

Scheme 12 Key step of the stereoselective enzymatic total synthesis of bisorbicillinol 94 and sorbiquinol 95 . 

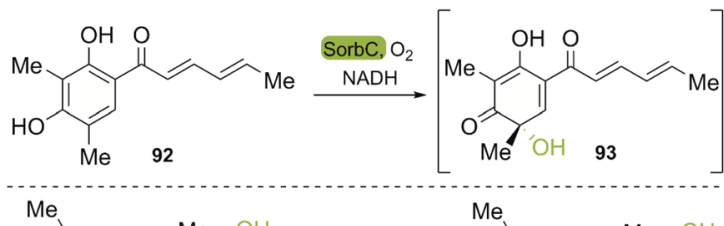

$\mathrm{Me}$

Me

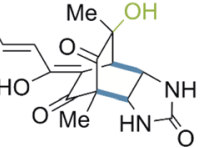

96, Urea sorbicillinoid, $21 \%$

Me

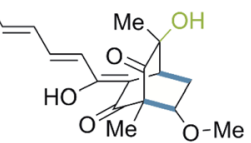

98. Rezishanone C. $29 \%$

Scheme 13 Chemoenzymatic synthesis of the sorbicillinoids via enantioselective oxidative dearomatization of sorbicillin with SorbC and $\mathrm{DA}$ reaction.

byproducts. As an example, the use of DMF combined with the work-up comprising extraction with $\mathrm{CH}_{2} \mathrm{Cl}_{2}$, a fast evaporation of $\mathrm{CH}_{2} \mathrm{Cl}_{2}$ after $4 \mathrm{~h}$, and the subsequent heating in the presence of pyridine furnished sorbiquinol 95 in $7 \%$ yield. This chemoenzymatic approach proved to be an excellent alternative in comparison to the chemical syntheses reported to date. For example, the Deng group reported an elegant enantioselective total synthesis of bisorbicillinol 94 with a global yield of $27 \%$, however applying 10 steps. ${ }^{52}$

In 2018, the groups of Gulder and Narayan independently reported a chemoenzymatic approach towards the synthesis of new sorbicillin derivates. ${ }^{53,54}$ In these investigations, the use of the SorbC enzyme once again furnished sorbicillinol 93 by oxidative dearomatization as a key step. The use of $\mathrm{CH}_{2} \mathrm{Cl}_{2}$ enabled the extraction of 93; and its subsequent reaction with different dienophiles allowed the production of sorbicillin derivates in a simple chemoenzymatic process. The scope of products was very versatile, giving access to urea sorbicillinoid 96, sorbicatechol A 97, and rezishanone C 98 (Scheme 13).

The Narayan-group synthesized the urea sorbicillinoid 96 via a DA reaction between sorbicillin and bisacylated urea and following by the addition of LiOH. Furthermore, they described different monooxygenases, such as Trop B and AzaH, for the catalysis of the oxidative dearomatization of resorcinols, allowing for the synthesis of valuable ortho-quinol products, ${ }^{54}$ a process that was adapted to gram scale.

3.2.2 DA/HDA and hydrolases. In 2002 Caille et al. ${ }^{55}$ reported the chemoenzymatic synthesis of ethyl $(S)$-3,6-dihydro$2 \mathrm{H}$-pyran-2-carboxylate 101, which is a useful intermediate in the synthesis of macrocyclic bisindolylmaleimide (LY333531) 103, a potent inhibitor of protein kinase $\mathrm{C} \beta$ (PKC $\beta) .{ }^{56}$ The bioclick approach developed by Caille et al. took advantage of inexpensive starting materials, namely butadiene 99 and ethyl glyoxylate 100, producing 2-carboethoxy 3,6-dihydro- $2 H$-pyran 101 in a HAD-reaction. The subsequent resolution of the racemic ester by selective enzymatic hydrolysis using $B$. lentus
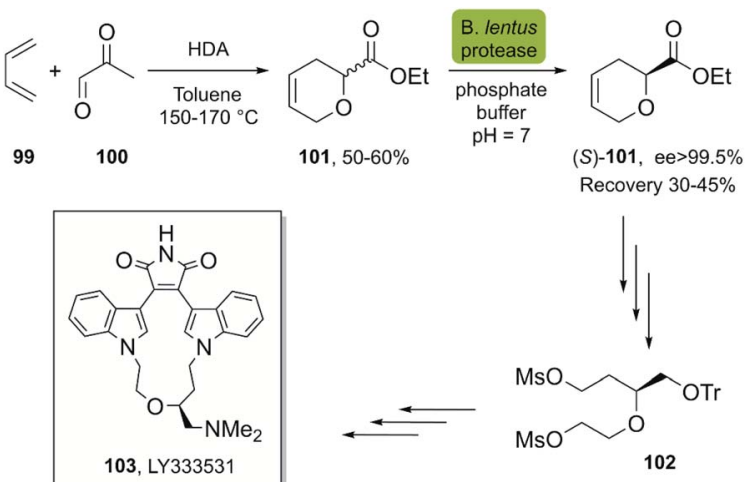

Recovery $30-45 \%$

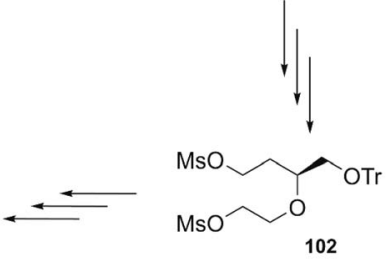

Scheme 14 Chemoenzymatic synthesis of (S)-101, a key intermediate in the synthesis of LY333531, a protein kinase C inhibitor (PKC $\beta$ ).

protease was carried out on a gram-scale, and after $8 \mathrm{~h}$ the ee of the $(S)$-configured ester was $>99.5 \%$ (Scheme 14 ).

In 2010, Wirz et al. reported the scalable enantioselective synthesis of a benzothiazole derivative 109, which was evaluated as an A2 receptor antagonist for the treatment of major depression. ${ }^{57}$ The developed chemoenzymatic process consists of the DA-reaction of furan $\mathbf{1 0 4}$ with acrylonitrile 105, activated by $\mathrm{ZnCl}_{2}$, furnishing bicyclic product 106. The following steps gave rise to the racemic product $\mathbf{1 0 7}$, which was hydrolyzed by CALA lipase in a stereoselective fashion, furnishing the $(S)$ enantiomer 108 with excellent enantioselectivity (Scheme 15).

Abacavir is a carbocyclic nucleoside with antiviral activity, acting as a reverse transcriptase inhibitor (see Scheme 16). It is used in combinations with other nucleoside analogues, such as lamivudine, for the treatment of HIV-infection. ${ }^{58}$ Crimmins et al. described an asymmetric synthesis of abacavir in 1996, making use of a first-generation Grubbs catalyst. ${ }^{59}$ An alternative synthetic route (Scheme 16a), used the Vince lactam 111, which can be obtained by the DA reaction of cyclopentadiene 110 and tosyl cyanide. ${ }^{60}$ The subsequent enzymatic kinetic resolution of the racemic Vince lactam with lactamase furnished the corresponding amino acid $\mathbf{1 1 3}$ (with (-) lactamase) or the (-) Vince lactam 112 (using (+) lactamase), which was then hydrolyzed into the desired amino acid $113 .^{61}$ This key

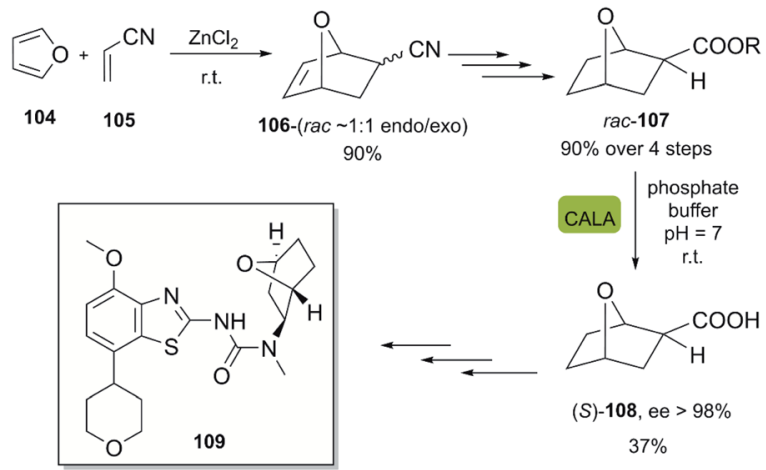

Scheme 15 Bio-click approach for the synthesis of (S)-108. Precursor in the synthesis of A2 receptor antagonist 109. 


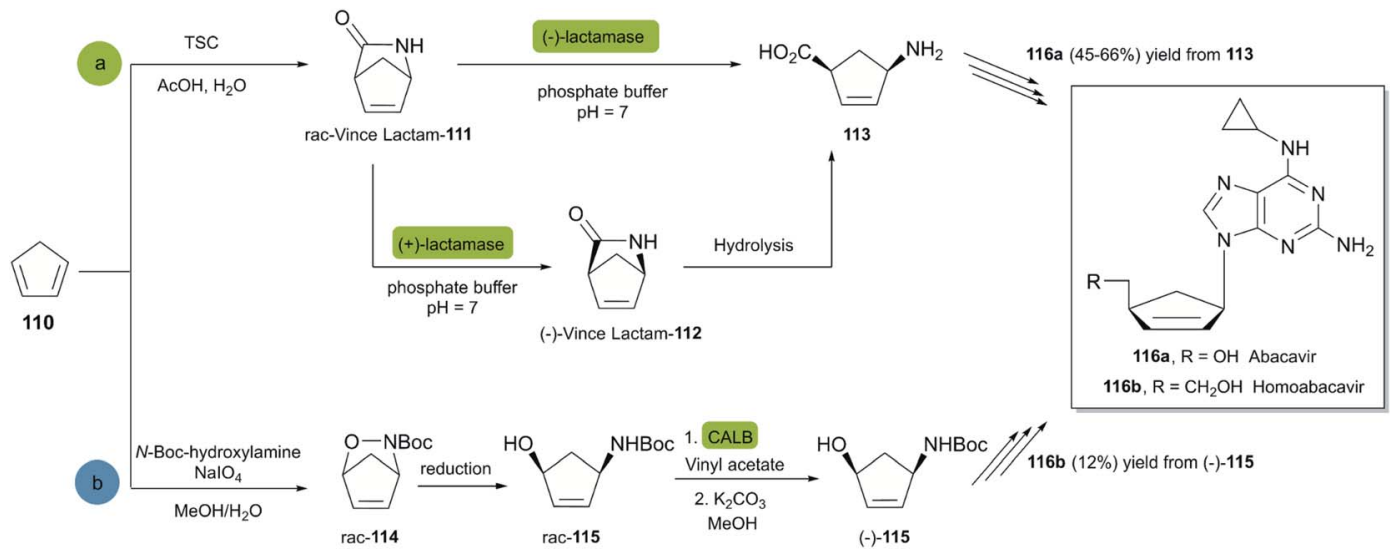

Scheme 16 Chemoenzymatic synthesis of abacavir. (a) Using a lactamase by kinetic resolution of rac-Vince lactam and (b) using a CALB lipase in the kinetic resolution of aminocyclopentenol derivate.

intermediate can then be converted into the desired product abacavir. ${ }^{62}$

The Vince lactam is not only a useful intermediate in the synthesis of abacavir, but also in the synthesis of peramivir and carbovir. In fact, numerous groups have reported the application of different lactamases for the resolution of the Vince lactam, en route to these powerful antiviral agents. ${ }^{63} \mathrm{~A}$ work carried out by Tardibono et al. ${ }^{64}$ presents a bio-click methodology towards homoabacavir 116b (Scheme 16b). In this approach, the hetero Diels Alder-reaction between cyclopentadiene and the transient nitroso-compound of $N$-Boc-hydroxylamine is used for the formation of intermediate 114. The subsequent reduction of the $\mathrm{N}-\mathrm{O}$ bond furnished the racemic aminocyclopentenol derivative 115, which was then successfully subjected to a kinetic resolution with CALB lipase, using vinyl acetate with posterior basic hydrolysis, furnishing 115-(-) (80\% ee) as a key intermediate for the further syntheses of homoabacavir 116b and homocarbovir. ${ }^{64}$

\subsection{Epoxide-opening and biocatalysis}

Epoxides are valuable and versatile building blocks and synthetic intermediates common in nature and synthesis. ${ }^{65,66}$ The outstanding reactivity of the three-membered ring is mainly caused by the special geometry and angle strain, endowing the ring opening reaction with a favourable thermodynamic driving force ( 24 to $28 \mathrm{kcal} \mathrm{mol}^{-1}$ ). ${ }^{67,68} \mathrm{The}_{\mathrm{N}} 2$ ring opening of epoxides shows a variety of desirable characteristics, such as reliability, stereospecificity and regioselectivity. ${ }^{4}$ The congener aziridines present similar characteristics, however with the advantage of the presence of a nitrogen atom, allowing subsequent chemical transformations in a somewhat easier way ${ }^{69,70}$ Nevertheless, fewer efficient methods for the direct synthesis of aziridines are available ${ }^{71}$ also reflected in the scarce number of respective bioclick approaches incorporating these substrates. The recent development of methods for the enzyme-catalyzed olefin aziridination ${ }^{72}$ could change these shortcomings and foster the development of a greater number of bio-click approaches incorporating aziridines.
The ring-opening of epoxides has been extensively applied for the synthesis of complex molecules..$^{73}$ In fact, the synthesis of numerous Active Pharmaceutical Ingredients (APIs) uses ring-opening of epoxides as a key step. ${ }^{747}$ The bio-click approach towards the ring-opening reaction of epoxides is a field of increasing interest.

Generally, the bio-click approach incorporating epoxides is applied in two ways: (a) the selective enzymatic oxidation of alkenes, furnishing epoxides in green conditions for the subsequent ring opening; (b) the oxidation of alkenes, a subsequent enzymatic resolution of the racemic epoxides and the ring-opening of the desired candidate (Scheme 17).

3.3.1 Epoxide-opening and oxidoreductases. The oxidoreductases are useful for the synthesis of enantiopure epoxides. ${ }^{76}$ Also, the enantioselective biooxidation of alkenes has been used as a key step in the bio-inspired synthesis of natural products. ${ }^{77,78}$ The directed evolution and rational design of enzymes has allowed the optimization of selectivity, catalytic efficiency and stability of oxidoreductases towards the levels necessary for industrial applications. ${ }^{79,80}$ Regarding the bio-click approach, the direct or indirect synthesis of epoxides using oxidoreductases is predominant. However, the biooxidation, chemical epoxidation and ring opening approach has been used in the total synthesis of molecules with multiple contiguous stereocenters.

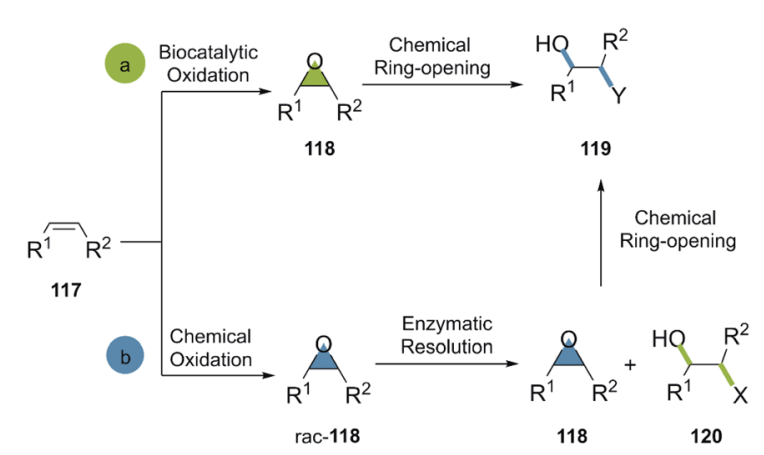

Scheme 17 General bio-click approach in epoxide-opening reactions. 
cis-1,2-Dihydrocatechols $\mathbf{4 6}$ are obtained by the enzymatic dihydroxylation of arenes $\mathbf{4 5}$ and represent an excellent platform for the synthesis of alkaloids, sugars, cyclitols, prostaglandins, terpenes, polymers and others (Scheme 18a). ${ }^{81}$ As an example, the enantioselective synthesis of cis-1,2-dihydrocatechols is carried out in a whole-cell fermentation, which provides an efficient cofactor regeneration system. ${ }^{82} \mathrm{E}$. coli JM109 (pDT601) which contains the genes from Pseudomonas putida F1 for the overexpression of the toluene dioxygenase system (TDO), ${ }^{83}$ is the most common biocatalyst applied for the enantioselective synthesis of cis-1,2-dihydrocatechol derivates. Careful optimization of the reaction conditions in a biphasic system can achieve yields as high as $35 \mathrm{~g} \mathrm{~L}^{-1} .^{84}$ This is quite remarkable, considering that no efficient chemical method is known for the production of this class of compounds at scale. ${ }^{79,81}$

The cis-1,2-dihydrocatechols are highly versatile and a great platform for enantioselective synthesis ${ }^{85}$ (Scheme 18b). Monoepoxidation, for example, is a transformation that can be easily applied to cis-1,2-dihydrocatechols 121 and combined with enantio- and regioselective 122 ring-openings, which can be efficiently applied in total synthesis. ${ }^{\mathbf{8 6}}$

For the ring opening of the epoxides on dihydrocatechols 122 the general preference is towards the cleavage in the $5 \mathrm{a}$ position (see Scheme 18b), mainly associated to two factors: (a) the greater stabilization of the transient carbocation in the allylic position; (b) less steric hindrance at position 5a as compared to 6a. In this way, the cleavage of epoxides is generally achieved with high regio- and enantioselectivity, providing the corresponding products of the trans-1,2 addition efficiently. ${ }^{86}$

Representative examples for the opening of monoepoxides 122 (obtained from biocatalytic enzymatic cis-dihydroxylation of benzene derivates 45 ) with different nucleophiles are ubiquitous (see Scheme 18 , vitamin $\mathrm{C},{ }^{87}$ codeine, ${ }^{88}$ narseronine, ${ }^{89} \mathrm{C} 2$ epimer of aminocyclitol ${ }^{90}$ ) and crucial in the synthesis of natural products.

The indirect epoxidation of $\alpha$-haloketones using ketoreductases (KREDs) has become a common strategy to obtain chiral epoxides, also reflected in the stereoselective synthesis of different APIs obtained on a kg-scale. The development of new

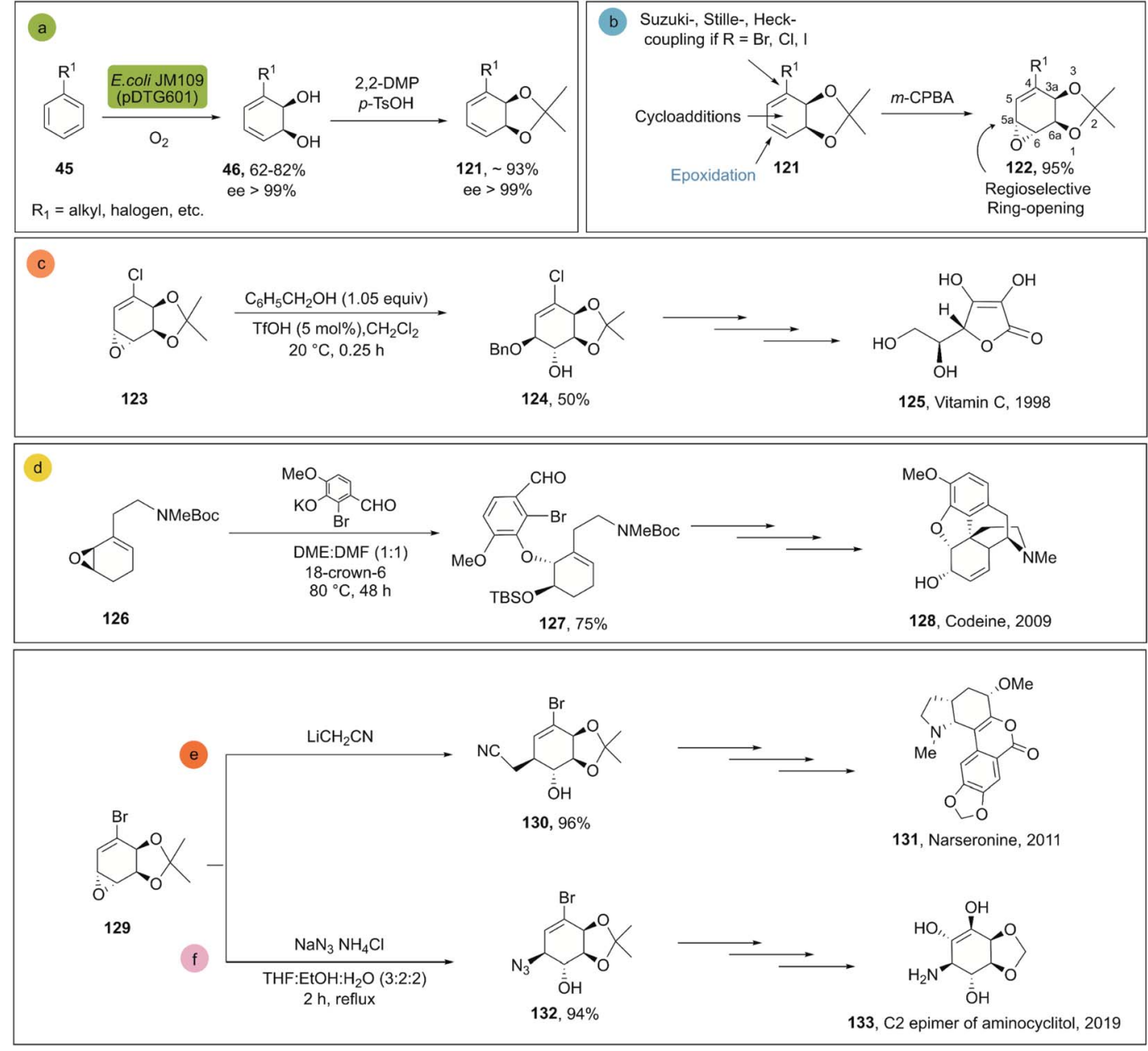

Scheme 18 (a) Biocatalytic dihydroxylation of arenes by E. coli JM109 (pDT601), (b) chemical reactivity of cis-1,2-dihydrocatechols. Representative molecules obtained from bio-click methodologies (TDO-ring opening). (c) Vitamin C 1998 by Longmore et al. ${ }^{87}$ (d) codeine 2009 by Leisch; $^{88}$ (e) narseronine 2011 by Schwartz et al. ${ }^{89}$ (f) C2 epimer of aminocyclitol 2019 by Carrau. ${ }^{90}$ 

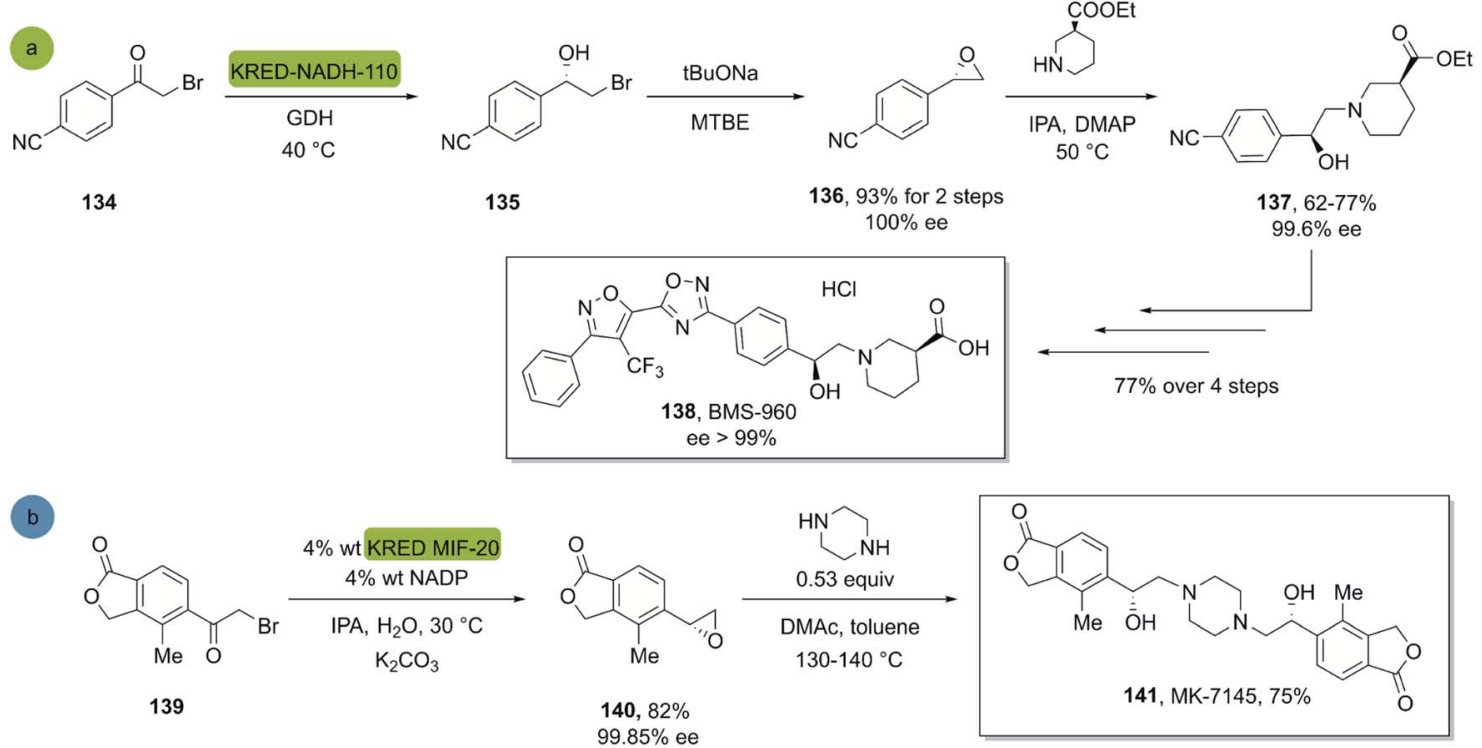

Scheme 19 KRED mediated epoxidation of alfa-bromo ketones and ring opening: (a) synthesis of BMS-960, (b) synthesis of MK7145.

variants of KREDs through protein engineering has widely enhanced scope, robustness, and selectivity of these biocatalysts. The fact that they are an excellent green alternative to conventional catalysts is further underscored by the easy workup, generally avoiding chromatographic product purifications.

In 2017, Hou et al. reported a chemo-enzymatic synthesis of BMS960, a powerful $\mathrm{S}_{1} \mathrm{P}_{1}$-receptor agonist. ${ }^{91}$ Its synthesis involved the enzymatic reduction of $\alpha$-bromoketone $134(100 \mathrm{~g}$ in $5 \mathrm{~h}$ at $40{ }^{\circ} \mathrm{C}$ ) to the corresponding alcohol 135 using the commercially available KRED-NADH-110 (substrate enzyme ratio $200: 1$ ). The chiral alcohol was then extracted with MTBE and reacted with sodium tert-butoxide towards the epoxide with $93 \%$ overall yield and $100 \%$ ee ( $S$-enantiomer). Subsequently, a regio- and stereospecific ring opening of the epoxide 136 with $(S)$-ethyl piperidine-3-carboxilate in the presence of a catalytic amount of DMAP at $50{ }^{\circ} \mathrm{C}$, provided the product 137 in up to $77 \%$ yield and with an ee of $99.6 \%$ after recrystallization. Four successive chemical transformations furnished BMS-960 in 23$33 \%$ overall yield (Scheme 19a).

In 2020, Ruck et al. reported a kg-scale synthesis of MK-7145, a clinical candidate for the treatment of hypertension and associated heart failures. ${ }^{92}$ The synthesis involved the enzymatic reduction of a bromo-ketone $\mathbf{1 3 9}$ to the corresponding bromohydrin as a key step. The commercial KRED-MIF-20induced reduction and a subsequent ring closure furnished the corresponding enantiopure epoxide in $82 \%$ yield and excellent enantiopurity. Subsequently the target molecule MK7145141 was obtained through a bis-epoxide opening with piperazine at $140{ }^{\circ} \mathrm{C}$, furnishing the product in $75 \%$ yield (Scheme 19b).

Similar to the abovementioned biocatalytic cis-dihydroxylation of arenes 142, the Hollmann group recently described the direct biocatalytic epoxidation of naphthalene derivatives. ${ }^{93}$ The methodology described is based on the recombinantly evolved peroxygenase variant PaDa-I from Agrocybe aegerita (rAaeUPO), a self-sufficient enzyme. Careful control of the reaction time of the nucleophilic addition allows for the generation of the ring-opening products 144 using nucleophiles such as sodium azide (Scheme 20).

In this way, the synthesis of eleven derivatives in yields ranging from 6 to $73 \%$ was reported. These arene oxides are excellent building blocks for the synthesis of trans-disubstituted cyclohexadienes and can be further functionalized towards triazoles, amino alcohols, and other valuable entities. Epichlorohydrin 145 is a versatile molecule with multiple applications, ${ }^{\mathbf{9 4}}$ and a useful starting material for the synthesis of different APIs.

The synthesis of rivaroxaban, an anticoagulant widely used in the prophylaxis of cardiovascular diseases, ${ }^{95}$ has been described by numerous groups using $(R)$-epichlorohydrin 145 as a building block. ${ }^{96}$ In a bio-click approach, rivaroxaban was synthesized via $(R)-\mathbf{1 4 5}$, which can be obtained either by an enantioselective biooxidation of 3-chloropropene 146 using chloroperoxidase CPO from Caldariomyces fumago, ${ }^{97}$ or by resolution of racemic 145 using epoxyhydrolase $\mathrm{EH} \mathrm{ArEH}^{\mathbf{9 8}}$ from Agrobacterium radiobacter (Scheme 21). Further functionalisation of the desired epoxide with phthalimide under basic conditions using a phase transfer agent and a subsequent regioand enantiospecific ring opening of epoxide 148 with arylamine

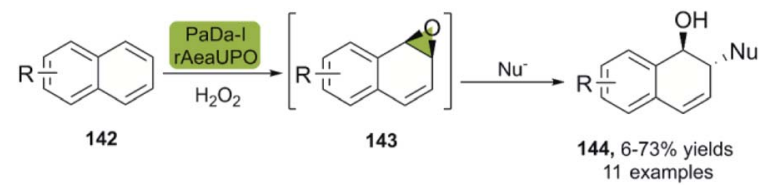

Scheme 20 Bio-click synthesis of trans-disubstituted cyclohexadiene derivatives using peroxygenase $\mathrm{PaDa}-\mathrm{I}$, and chemical ring-opening with different nucleophiles. 

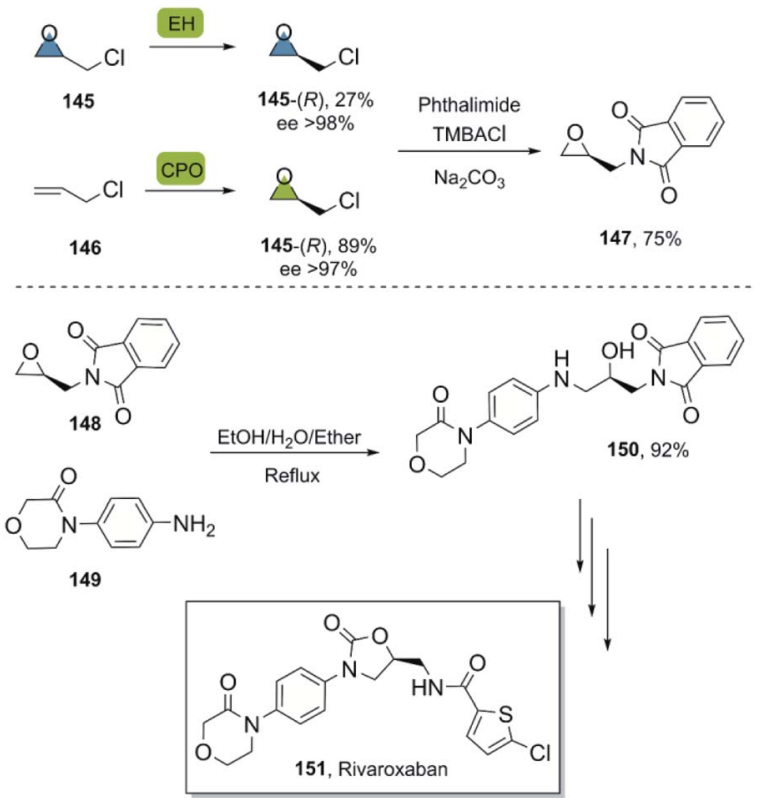

Scheme 21 Bio-click approach for the synthesis of rivaroxaban.

149, furnished the product 150 smoothly en route to rivaroxaban. ${ }^{99}$

3.3.2 Epoxide-opening and hydrolases. In 2012, Porcar et $a l .{ }^{\mathbf{1 0 0}}$ reported the stereoselective chemoenzymatic synthesis of imidazoles under continuous flow conditions for the generation of new chiral ionic liquids. ${ }^{101}$ The first step is the epoxide opening of cyclohexene oxide 152 with imidazole 153 in a continuous flow reactor with microwave (MW) irradiation (Scheme 22). The resulting cyclohexanol derivative $( \pm)$-trans-154 is then subjected to the second step, an acylation with vinyl acetate catalyzed by the commercially available immobilized lipases Novozym ${ }^{\circledR} 435$ or PSL-CI (Pseudomonas cepacia lipase), allowing an efficient kinetic resolution. The applied continuous-flow methodology demonstrated high efficiency in a batch process, and the lipases provided the corresponding acylated kinetically-resolved product 155 with excellent enantioselectivities (>99\%) and virtually complete conversion.

In 2015 , Villar et al. reported the chemoenzymatic synthesis of optically pure, orthogonally protected trans-3-amino-4hydroxypiperidines, potential molecules for the synthesis of chiral bioactive compounds (Scheme 23). ${ }^{\mathbf{1 0 2}}$ The developed bioclick methodology developed, starts with the regioselective epoxide-opening with diallylamine, providing access to the racemic trans-cyclohexanol 157. The subsequent enzymatic kinetic resolution via transesterification with vinyl acetate was performed with Novozym ${ }^{\circledR} 435$, which gave the desired product 158 with the highest conversion (47\%) and enantioselectivity (ee $>99 \%$ ) among the enzymes tested.

Propranolol is a versatile beta-adrenergic receptor antagonist used in the treatment of several cardiovascular such as hypertension, cardiac arrhythmias, etc.103 Quite remarkably, $(S)$ propranolol is 100 times more potent $\beta$-adrenergic receptor blocker than its enantiomer. ${ }^{104}$ In 2015, Dong et al. ${ }^{105}$ reported

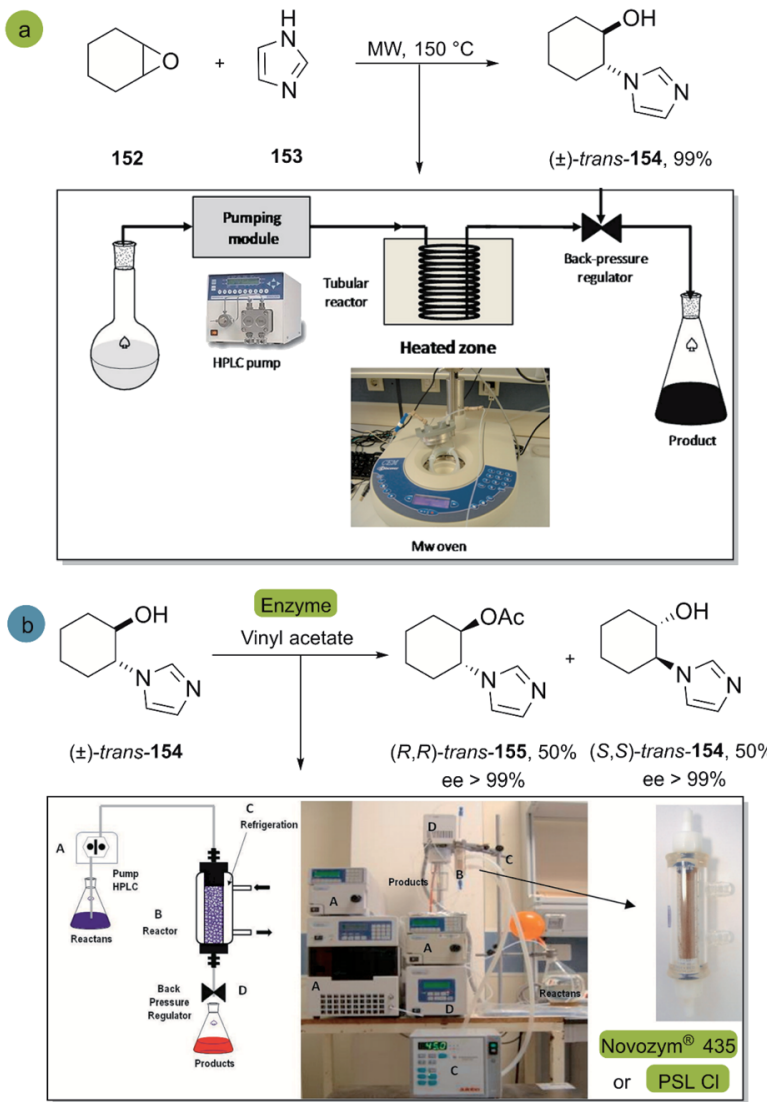

Scheme 22 Synthesis of trans-2-(1H-imidazol-1-yl)cyclohexanol (b) enantioselective acylation of $( \pm)$-trans-2-(1H-imidazol-1-yl)cyclohexanol 154 with vinyl acetate catalyzed by Novozym ${ }^{\circledR} 435$ or PSL-Cl. This figure was used with permission. ${ }^{100}$

the chemoenzymatic two-step synthesis of (S)-propranolol (Scheme 24). The enzymatic kinetic resolution of racemic epoxide 159 with the hydrolase BmEH128T (from Bacillus megaterium), smoothly furnished the $(S)$-configured product 159 smoothly after centrifugation of the undesired enantiomer. The subsequent regioselective ring-opening of $(S)$-159 with isopropylamine under reflux conditions gave $(S)$-propanolol 160 in an overall yield of $42 \%$ and excellent enantioselectivity after recrystallization (ee $>99 \%$ ).

\subsection{Thiol-Michael reactions and biocatalysis}

Thiol-Michael click reactions, either via free-radical, or catalyzed Michael-additions, are valuable transformations widely

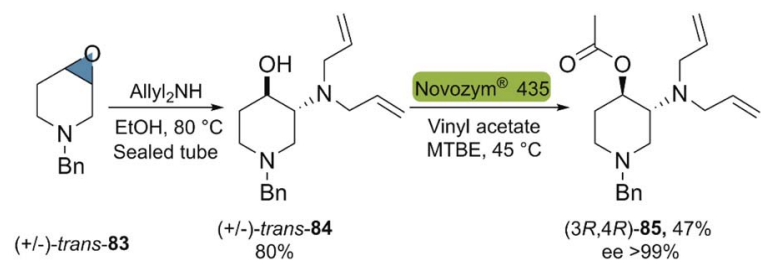

Scheme 23 Chemoenzymatic synthesis of optically pure orthogonally protected trans-3-amino-4-hydroxypiperidines. 


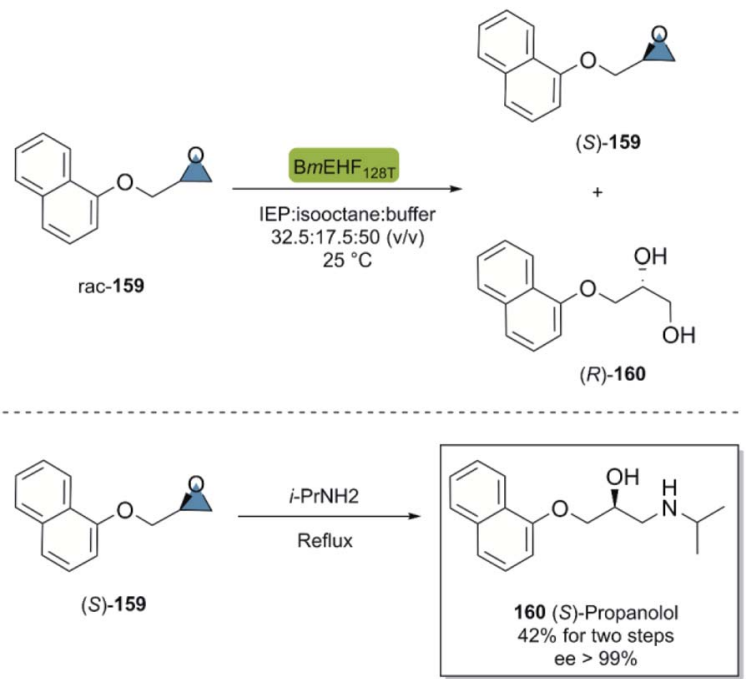

Scheme 24 Chemoenzymatic synthesis of (S)-propranolol.

recognized in polymer science and bioconjugation chemistry, since they allow for the efficient formation of C-S bonds from thiols and alkenes (Scheme 25). ${ }^{106-108}$ They are usually highly efficient, work under mild reaction conditions, are regioselective and atom-economic, and only generate few or no byproducts which are generally easily separated. ${ }^{109,110}$ Bio-click reactions approaches featuring thiol-Michael chemistry are scarce to date, despite the advantages of chemoenzymatic reactions in this context.

3.4.1 Thiol-Michael reactions and oxidoreductases. The spatial and temporal control of light as an energy source for thiol-Michael click reactions proved valuable in tandem bioclick reactions, as reported in 2018 by Lauder et al. for the synthesis of volatile chiral 1,3-mercaptoalkanols 166-167. ${ }^{111}$ The reported one-pot methodology comprises a thiol-Michael reaction photocatalyzed by visible light combined with $\left[\mathrm{Ru}(\mathrm{bpy})_{3}\right] \mathrm{Cl}_{2}(0.3 \mathrm{~mol} \%)$, fully compatible with the conditions of the subsequent bioreduction using KREDs (see Scheme 26). The enzymes used furnished the corresponding $(S)$ - or $(R)$ enantiomers in yields (38-73\%) and high enantiomeric excess.

\section{Summary and outlook}

This review summarizes developments in a field of research that combines biocatalytic transformations and click reactions. The proposal of the term bio-click chemistry comes quite naturally if one considers the varied and efficient syntheses of complex molecules explored. A clear classification of the different chemoenzymatic transformations will undoubtedly promote the

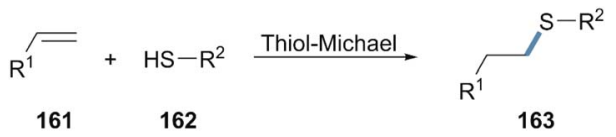

Scheme 25 Thiol-Michael click chemistry.

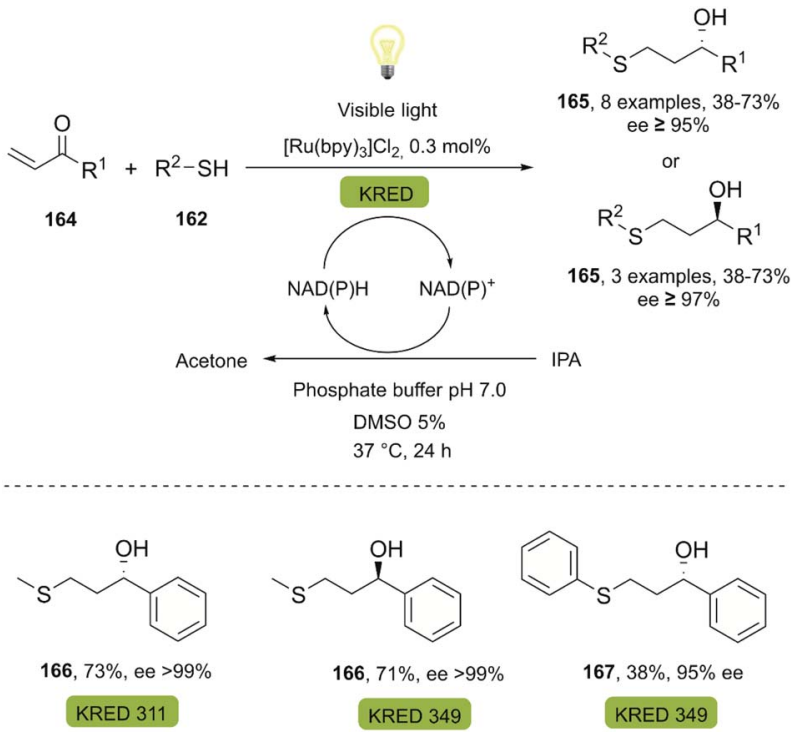

Scheme 26 One-pot photo-biocatalytic (thiol-Michael/KRED reduction).

development of more sustainable and efficient processes in this area (see Table 1).

Bio-click chemistry reactions are demonstrated to be remarkably complementary, as is the case of click chemical reactions, which are regiospecific by nature but not necessarily enantioselective. The joint use of enzymes/microorganisms

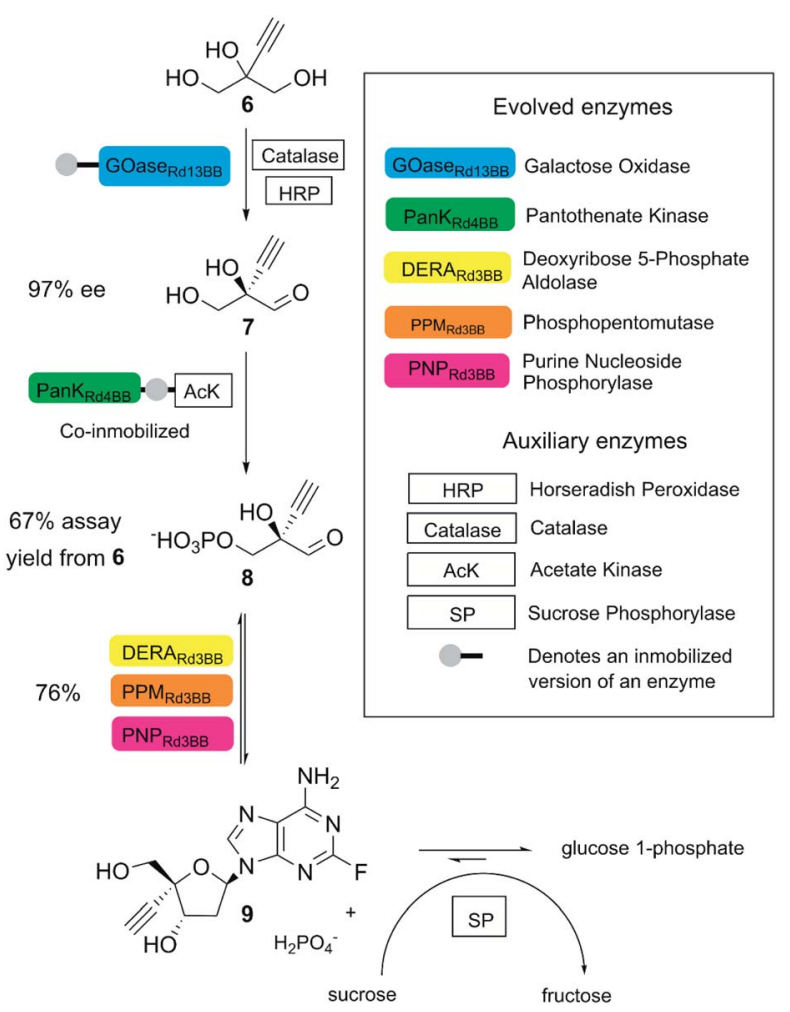

Fig. 3 Biocatalytic synthesis of islatravir. (This figure has been adapted from ref. 22. With permission from Science Journal, copyright 2020). 
Table 1 Representative molecules obtained via bio-click chemistry

Click reaction Enzyme or microorganism $\quad$ Structure

Function

Reference

CuAAC Carbonyl reductase from Candida magnoliae (CMCR)

$(+)-\gamma$-Lactamase, $(-)-\gamma$-lactamase from Bradyrhizobium japonicum USDA 6 Candida antarctica B lipase (CALB)

Oxidoreductase SorbC

E. coli JM109 (pDTG601)

Epoxide-opening

Ketoreductase, KRED-NADH-110

Thiol-Michael

Ketoreductase, KRED-311<smiles>OCc1cn(C[C@@H](O)c2ccc(Cl)cc2)nn1</smiles>

$\beta$-Adrenergic receptor blocker analogue

$\beta$-blocker triazol analog<smiles>Nc1nc(NC2CC2)c2ncn(C34C=CC(CO)CC3C4)c2n1</smiles>

$58,60,61$ and 112

64

Carbocyclic nucleoside with antiviral activity

Antiviral activity against

3, 54 and<smiles>COc1cc(C(C)C(C)=O)ccc1O</smiles>
H1N1

Sorbicatechol A<smiles>COc1ccc2c3c1O[C@H]1[C@H](O)C=CC(C2)[C@]31CCN</smiles>

Painkiller

88

Codeine
113

91

BMS-960<smiles>C[C@@H](O)CCSc1ccccc1</smiles>

Volatile sulfur compound 111

1,3-mercaptoalkanol

allows to overcome these limitations, introducing chirality without hampering the overall efficiency of the processes. The global need of, and tendency towards more sustainable and green processes is thoroughly reflected by the complementary use of efficient chemical reactions and green biocatalysis. It can be envisioned, that the development of more robust and active biocatalysts with wider substrate ranges will facilitate the broadening of efficient bio-click processes foreseeable future. A very promising example are ketoreductases (KREDs), which are by now widely commercially available in great variety. The use of KREDs has proven to be a competitive alternative to conventional enantioselective oxidations, even on an industrial scale.

It is essential to emphasize, that click reactions, biocatalysis or their combination do not generate greener processes per se, and it is always necessary to carefully evaluate the exact methodology, the implementation in a reaction sequence and the expected overall efficiency and sustainability for future improvements. 


\section{Conflicts of interest}

There are no conflicts to declare.

\section{Acknowledgements}

FZ is grateful to ANID/CONICYT/FONDECYT Regular No. 1210763. DR thanks CONICYT-PCHA/Doctorado Nacional/201821180422. CARS is supported by ANID Millennium Science Initiative Program ICN17_022. We also want to thank Lars Ratjen PhD for the English revision of this manuscript.

\section{Notes and references}

1 M. Hönig, P. Sondermann, N. J. Turner and E. M. Carreira, Angew. Chem., Int. Ed., 2017, 56, 8942-8973.

2 U. T. Bornscheuer, G. W. Huisman, R. J. Kazlauskas, S. Lutz, J. C. Moore and K. Robins, Nature, 2012, 485, 185.

3 M. Cortes-Clerget, N. Akporji, J. Zhou, F. Gao, P. Guo, M. Parmentier, F. Gallou, J.-Y. Berthon and B. H. Lipshutz, Nat. Commun., 2019, 10, 2169.

4 H. C. Kolb, M. G. Finn and K. B. Sharpless, Angew. Chem., Int. Ed., 2001, 40, 2004-2021.

5 H. C. Erythropel, J. B. Zimmerman, T. M. de Winter, L. Petitjean, F. Melnikov, C. H. Lam, A. W. Lounsbury, K. E. Mellor, N. Z. Janković, Q. Tu, L. N. Pincus, M. M. Falinski, W. Shi, P. Coish, D. L. Plata and P. T. Anastas, Green Chem., 2018, 20, 1929-1961.

6 E. Oueis, C. Sabot and P.-Y. Renard, Chem. Commun., 2015, 51, 12158-12169.

7 J. M. Palomo, Curr. Org. Chem., 2013, 17, 691-700.

8 J. L. Brennan, N. S. Hatzakis, T. R. Tshikhudo, V. Razumas, S. Patkar, J. Vind, A. Svendsen, R. J. M. Nolte, A. E. Rowan and M. Brust, Bioconjugate Chem., 2006, 17, 1373-1375.

9 J. M. Palomo, Org. Biomol. Chem., 2012, 10, 9309-9318.

10 R. B. Woodward, W. A. Ayer, J. M. Beaton, F. Bickelhaupt, R. Bonnett, P. Buchschacher, G. L. Closs, H. Dutler, J. Hannah, F. P. Hauck, S. Itô, A. Langemann, E. Le Goff, W. Leimgruber, W. Lwowski, J. Sauer, Z. Valenta and H. Volz, J. Am. Chem. Soc., 1960, 82, 3800-3802.

11 K. C. Nicolaou, Z. Yang, J. J. Liu, H. Ueno, P. G. Nantermet, R. K. Guy, C. F. Claiborne, J. Renaud, E. A. Couladouros, K. Paulvannan and E. J. Sorensen, Nature, 1994, 367, 630634.

12 R. A. Holton, H. B. Kim, C. Somoza, F. Liang, R. J. Biediger, P. D. Boatman, M. Shindo, C. C. Smith and S. Kim, J. Am. Chem. Soc., 1994, 116, 1599-1600.

13 T. Durek, V. Y. Torbeev and S. B. H. Kent, Proc. Natl. Acad. Sci. U. S. A., 2007, 104, 4846-4851.

14 R. Noyori, Nat. Chem., 2009, 1, 5-6.

15 P. Thirumurugan, D. Matosiuk and K. Jozwiak, Chem. Rev., 2013, 113, 4905-4979.

16 P. Prasher and M. Sharma, Medchemcomm, 2019, 10, 13021328.

17 R. K. Iha, K. L. Wooley, A. M. Nyström, D. J. Burke, M. J. Kade and C. J. Hawker, Chem. Rev., 2009, 109, 56205686.
18 M. A. Tasdelen, B. Kiskan and Y. Yagci, Prog. Polym. Sci., 2016, 52, 19-78.

19 R. A. Sheldon and J. M. Woodley, Chem. Rev., 2018, 118, 801-838.

20 C. A. Martinez, S. Hu, Y. Dumond, J. Tao, P. Kelleher and L. Tully, Org. Process Res. Dev., 2008, 12, 392-398.

21 R. A. Sheldon, Green Biocatal., 2016, 1-13.

22 M. A. Huffman, A. Fryszkowska, O. Alvizo, M. Borra-Garske, K. R. Campos, K. A. Canada, P. N. Devine, D. Duan, J. H. Forstater, S. T. Grosser, H. M. Halsey, G. J. Hughes, J. Jo, L. A. Joyce, J. N. Kolev, J. Liang, K. M. Maloney, B. F. Mann, N. M. Marshall, M. McLaughlin, J. C. Moore, G. S. Murphy, C. C. Nawrat, J. Nazor, S. Novick, N. R. Patel, A. Rodriguez-Granillo, S. A. Robaire, E. C. Sherer, M. D. Truppo, A. M. Whittaker, D. Verma, L. Xiao, Y. Xu and H. Yang, Science, 2019, 366, 1255-1259.

23 M. K. M. Leung, C. E. Hagemeyer, A. P. R. Johnston, C. Gonzales, M. M. J. Kamphuis, K. Ardipradja, G. K. Such, K. Peter and F. Caruso, Angew. Chem., Int. Ed., 2012, 51, 7132-7136.

24 M. L. Blackman, M. Royzen and J. M. Fox, J. Am. Chem. Soc., 2008, 130, 13518-13519.

25 J. Dong, L. Krasnova, M. G. Finn and K. B. Sharpless, Angew. Chem., Int. Ed., 2014, 53, 9430-9448.

26 G. Meng, T. Guo, T. Ma, J. Zhang, Y. Shen, K. B. Sharpless and J. Dong, Nature, 2019, 574, 86-89.

27 N. M. Meghani, H. H. Amin and B.-J. Lee, Drug Discovery Today, 2017, 22, 1604-1619.

28 A. Brik, J. Alexandratos, Y.-C. Lin, J. H. Elder, A. J. Olson, A. Wlodawer, D. S. Goodsell and C.-H. Wong, ChemBioChem, 2005, 6, 1167-1169.

29 H. Ankati, Y. Yang, D. Zhu, E. R. Biehl and L. Hua, J. Org. Chem., 2008, 73, 6433-6436.

30 C. Aguirre-Pranzoni, R. D. Tosso, F. R. Bisogno, M. KurinaSanz and A. A. Orden, Process Biochem., 2019, 79, 114-117.

31 P. Sivaguru, Y. Ning and X. Bi, Chem. Rev., 2021, 121, 42534307.

32 W. Szymanski, C. P. Postema, C. Tarabiono, F. Berthiol, L. Campbell-Verduyn, S. de Wildeman, J. G. de Vries, L. Feringa and D. B. Janssen, Adv. Synth. Catal., 2010, 352, 2111-2115.

33 L. S. Campbell-Verduyn, L. Mirfeizi, R. A. Dierckx, P. H. Elsinga and L. Feringa, Chem. Commun., 2009, 21392141.

34 T. N. Nguyen, P.-A. Chen, K. Setthakarn and J. A. May, Molecules, 2018, 23.

35 K. Leijondahl, L. Borén, R. Braun and J.-E. Bäckvall, Org. Lett., 2008, 10, 2027-2030.

36 A. Cuetos, F. R. Bisogno, I. Lavandera and V. Gotor, Chem. Commun., 2013, 49, 2625-2627.

37 C. de Souza de Oliveira, K. T. de Andrade and A. T. Omori, J. Mol. Catal. B: Enzym., 2013, 91, 93-97.

38 V. de la Sovera, A. Bellomo, J. M. Pena, D. Gonzalez and H. A. Stefani, Mol. Diversity, 2011, 15, 163-172.

39 M. T. Sabatini, L. T. Boulton, H. F. Sneddon and T. D. Sheppard, Nat. Catal., 2019, 2, 10-17. 
40 D. S. Pedersen and A. Abell, Eur. J. Org. Chem., 2011, 2011, 2399-2411.

41 S. Hassan, R. Tschersich and T. J. J. Müller, Tetrahedron Lett., 2013, 54, 4641-4644.

42 P. Gesse and T. J. J. Müller, Eur. J. Org. Chem., 2019, 2019, 2150-2157.

43 N. N. Büyükadali, S. Seven, N. Aslan, D. Yenidede and A. Gümüs ş, Tetrahedron: Asymmetry, 2015, 26, 1285-1291.

44 M. E. Moisă, L. Poppe, C. A. Gal, L. C. Bencze, F. D. Irimie, C. Paizs, F. Peter and M. I. Toşa, React. Chem. Eng., 2018, 3, 790-798.

45 M. A. Tasdelen, Polym. Chem., 2011, 2, 2133-2145.

46 S. Otto, W. Blokzijl and J. B. F. N. Engberts, J. Org. Chem., 1994, 59, 5372-5376.

47 A. Wassermann, J. Chem. Soc., 1942, 618-621.

48 S. Otto and J. B. F. N. Engberts, Tetrahedron Lett., 1995, 36, 2645-2648.

49 P. Vermeeren, T. A. Hamlin, I. Fernández and F. M. Bickelhaupt, Angew. Chem., Int. Ed., 2020, 59, 62016206.

50 J. Meng, X. Wang, D. Xu, X. Fu, X. Zhang, D. Lai, L. Zhou and G. Zhang, Molecules, 2016, 21, 715.

51 A. Sib and T. A. M. Gulder, Angew. Chem., Int. Ed., 2017, 56, 12888-12891.

52 R. Hong, Y. Chen and L. Deng, Angew. Chem., Int. Ed., 2005, 44, 3478-3481.

53 A. Sib and T. A. M. Gulder, Angew. Chem., Int. Ed., 2018, 57, 14650-14653.

54 S. A. Baker Dockrey, A. L. Lukowski, M. R. Becker and A. R. H. Narayan, Nat. Chem., 2018, 10, 119-125.

55 J.-C. Caille, C. K. Govindan, H. Junga, J. Lalonde and Y. Yao, Org. Process Res. Dev., 2002, 6, 471-476.

56 M. R. Jirousek, J. R. Gillig, C. M. Gonzalez, W. F. Heath, J. H. McDonald, D. A. Neel, C. J. Rito, U. Singh, L. E. Stramm, A. Melikian-Badalian, M. Baevsky, L. M. Ballas, S. E. Hall, L. L. Winneroski and M. M. Faul, J. Med. Chem., 1996, 39, 2664-2671.

57 B. Wirz, P. Spurr and C. Pfleger, Tetrahedron: Asymmetry, 2010, 21, 159-161.

58 G. J. Moyle, E. DeJesus, P. Cahn, S. A. Castillo, H. Zhao, D. N. Gordon, C. Craig and T. R. Scott, JAIDS, J. Acquired Immune Defic. Syndr., 2005, 38, 417-425.

59 M. T. Crimmins and B. W. King, J. Org. Chem., 1996, 61, $4192-4193$.

60 R. Singh and R. Vince, Chem. Rev., 2012, 112, 4642-4686.

61 S. Zhu, L. Ren, S. Yu, C. Gong, D. Song and G. Zheng, Bioorg. Med. Chem. Lett., 2014, 24, 4899-4902.

62 S. M. Daluge, M. T. Martin, B. R. Sickles and D. A. Livingston, Nucleosides, Nucleotides Nucleic Acids, 2000, 19, 297-327.

63 S. Slagman and W.-D. Fessner, Chem. Soc. Rev., 2021, 50, 1968-2009.

64 L. P. Tardibono, M. J. Miller and J. Balzarini, Tetrahedron, 2011, 67, 825-829.

65 Y. Zou, M. Garcia-Borràs, M. C. Tang, Y. Hirayama, D. H. Li, L. Li, K. Watanabe, K. N. Houk and Y. Tang, Nat. Chem. Biol., 2017, 13, 325-332.
66 C. Bonini and G. Righi, Tetrahedron, 2002, 58, 4981-5021.

67 H. Pellissier, A. Lattanzi and R. Dalpozzo, in Asymmetric Synthesis of Three-Membered Rings, Wiley-VCH Verlag GmbH \& Co. KGaA, Germany, 1st edn, 2017, ch. 3, pp. 379-538.

68 K. M. Morgan, J. A. Ellis, J. Lee, A. Fulton, S. L. Wilson, P. S. Dupart and R. Dastoori, J. Org. Chem., 2013, 78, 4303-4311.

69 X. E. Hu, Tetrahedron, 2004, 60, 2701-2743.

70 P. Lu, Tetrahedron, 2010, 66, 2549-2560.

71 H. Pellissier, A. Lattanzi and R. Dalpozzo, in Asymmetric Synthesis of Three-Membered Rings, Wiley-VCH Verlag $\mathrm{GmbH} \&$ Co. KGaA, Germany, 1st edn, 2017, ch. 2, pp. 205-378.

72 C. C. Farwell, R. K. Zhang, J. A. McIntosh, T. K. Hyster and F. H. Arnold, ACS Cent. Sci., 2015, 1, 89-93.

73 P. Crotti and M. Pineschi, in Aziridines Epoxides Organic Synthesis, ed. A.K. Yudin, Wiley-VCH, Weinheim, 1st edn.2006, pp. 271-313.

74 M. G. Russell and T. F. Jamison, Angew. Chem., Int. Ed., 2019, 58, 7678-7681.

75 F. Moschona, I. Savvopoulou, M. Tsitopoulou, D. Tataraki and G. Rassias, Catal., 2020, 10, 1117-1182.

76 A. Archelas and R. Furstoss, Annu. Rev. Microbiol., 1997, 51, 491-525.

77 A. Archelas and R. Furstoss, Tetrahedron Lett., 1992, 33, 5241-5242.

78 F. J. Lakner and L. P. Hager, J. Org. Chem., 1996, 61, 39233925.

79 A. T. Martínez, F. J. Ruiz-Dueñas, S. Camarero, A. Serrano, D. Linde, H. Lund, J. Vind, M. Tovborg, O. M. HeroldMajumdar, M. Hofrichter, C. Liers, R. Ullrich, K. Scheibner, G. Sannia, A. Piscitelli, C. Pezzella, M. E. Sener, S. Kılıç, W. J. H. van Berkel, V. Guallar, M. F. Lucas, R. Zuhse, R. Ludwig, F. Hollmann, E. Fernández-Fueyo, E. Record, C. B. Faulds, M. Tortajada, I. Winckelmann, J.-A. Rasmussen, M. GeloPujic, A. Gutiérrez, J. C. del Río, J. Rencoret and M. Alcalde, Biotechnol. Adv., 2017, 35, 815-831.

80 R. A. Sheldon and D. Brady, ChemSusChem, 2019, 12, 28592881.

81 T. Hudlicky, ACS Omega, 2018, 3, 17326-17340.

82 F. F. Özgen and S. Schmidt, in Biocatalysis. Enzymatic Basics and Applications, ed. Q. Husain and M. F. Ullah, Springer International Publishing, New York, 1st edn, 2019, ch. 4, pp. 57-82.

83 G. J. Zylstra, W. R. McCombie, D. T. Gibson and B. A. Finette, Appl. Environ. Microbiol., 1988, 54, 1498-1503.

84 M. A. Vila, M. Brovetto, D. Gamenara, P. Bracco, G. Zinola, G. Seoane, S. Rodríguez and I. Carrera, J. Mol. Catal. B: Enzym., 2013, 96, 14-20.

85 T. Hudlicky, J. D. Price, F. Rulin and T. Tsunoda, J. Am. Chem. Soc., 1990, 112, 9439-9440.

86 M. G. Banwell, N. Haddad, T. Hudlicky, T. C. Nugent, M. F. Mackay and S. L. Richards, J. Chem. Soc., Perkin Trans. 1, 1997, 1779-1792. 
87 M. Banwell, S. Blakey, G. Harfoot and R. Longmore, J. Chem. Soc., Perkin Trans. 1, 1998, 3141-3142.

88 H. Leisch, A. T. Omori, K. J. Finn, J. Gilmet, T. Bissett, D. Ilceski and T. Hudlický, Tetrahedron, 2009, 65, 98629875.

89 B. D. Schwartz, M. G. Banwell and I. A. Cade, Tetrahedron Lett., 2011, 52, 4526-4528.

90 G. Carrau, A. I. Bellomo, L. Suescun and D. Gonzalez, Eur. J. Org. Chem., 2019, 2019, 788-802.

91 X. Hou, H. Zhang, B.-C. Chen, Z. Guo, A. Singh, A. Goswami, J. L. Gilmore, J. E. Sheppeck, A. J. Dyckman, P. H. Carter and A. Mathur, Org. Process Res. Dev., 2017, 21, 200-207.

92 R. T. Ruck, Q. Chen, N. Rivera, J. Kong, I. K. Mangion, L. Tan and F. J. Fleitz, Org. Process Res. Dev., 2021, 25, 405-410.

93 W. Zhang, H. Li, S. H. H. Younes, P. Gómez de Santos, F. Tieves, G. Grogan, M. Pabst, M. Alcalde, A. C. Whitwood and F. Hollmann, ACS Catal., 2021, 11, 2644-2649.

94 N. Kasai, T. Suzuki and Y. Furukawa, J. Mol. Catal. B: Enzym., 1998, 4, 237-252.

95 E. Perzborn, S. Roehrig, A. Straub, D. Kubitza and F. Misselwitz, Nat. Rev. Drug Discovery, 2010, 10, 61.

96 T. A. Fattah and A. Saeed, Tetrahedron: Asymmetry, 2017, 28, 485-504.

97 J. Wu, C. Liu, Y. Jiang, M. Hu, S. Li and Q. Zhai, Catal. Commun., 2010, 11, 727-731.

98 H.-X. Jin, Z.-Q. Liu, Z.-C. Hu and Y.-G. Zheng, Eng. Life Sci., 2013, 13, 385-392.

99 A. C. Mali, D. G. Deshmukh, D. R. Joshi, H. D. Lad, P. I. Patel, V. J. Medhane and V. T. Mathad, Sustainable Chem. Processes, 2015, 3, 11.
100 R. Porcar, V. Sans, N. Ríos-Lombardía, V. Gotor-Fernández, V. Gotor, M. I. Burguete, E. García-Verdugo and S. V Luis, ACS Catal., 2012, 2, 1976-1983.

101 E. Busto, V. Gotor-Fernández, N. Ríos-Lombardía, E. García-Verdugo, I. Alfonso, S. García-Granda, A. Menéndez-Velázquez, M. I. Burguete, S. V Luis and V. Gotor, Tetrahedron Lett., 2007, 48, 5251-5254.

102 Á. Villar-Barro, V. Gotor and R. Brieva, Tetrahedron, 2015, 71, 6907-6912.

103 A. V Srinivasan, Ann. Indian Acad. Neurol., 2019, 22, 21-26.

104 B. Silber, N. H. G. Holford and S. Riegelman, J. Pharm. Sci., 1982, 71, 699-704.

105 X.-D. Kong, H.-L. Yu, S. Yang, J. Zhou, B.-B. Zeng and J.-H. Xu, J. Mol. Catal. B: Enzym., 2015, 122, 275-281.

106 E. J. Park, T. N. Gevrek, R. Sanyal and A. Sanyal, Bioconjugate Chem., 2014, 25, 2004-2011.

107 S. S. Ghosh, P. M. Kao, A. W. McCue and H. L. Chappelle, Bioconjugate Chem., 1990, 1, 71-76.

108 D. P. Nair, M. Podgórski, S. Chatani, T. Gong, W. Xi, C. R. Fenoli and C. N. Bowman, Chem. Mater., 2014, 26, 724-744.

109 C. E. Hoyle and C. N. Bowman, Angew. Chem., Int. Ed., 2010, 49, 1540-1573.

110 E. K. Skinner, F. M. Whiffin and G. J. Price, Chem. Commun., 2012, 48, 6800-6802.

111 K. Lauder, A. Toscani, Y. Qi, J. Lim, S. J. Charnock, K. Korah and D. Castagnolo, Angew. Chem., Int. Ed., 2018, 57, 58035807.

112 R. Vince and M. Hua, Curr. Protoc. Nucleic Acid Chem., 2006, 25, 14.4.1-14.4.8.

113 J. Peng, X. Zhang, L. Du, W. Wang, T. Zhu, Q. Gu and D. Li, J. Nat. Prod., 2014, 77, 424-428. 